\title{
قراءة في بعض كتابات المفكر النمساوي \\ ليوبولد فايس (محمد أسد)
}

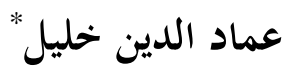

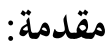

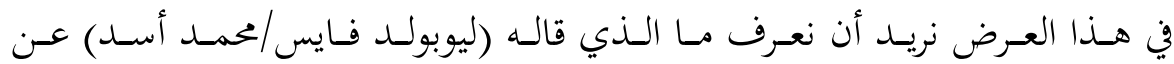
الإسلام، وهو المفكر الذي قدم عدداً مـ أكثر الدراسات التي عالجـت الإسلام إلمامـاً

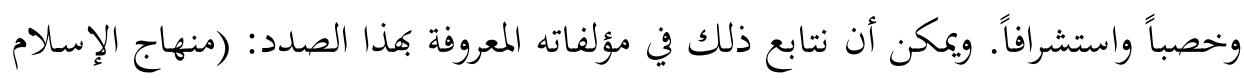

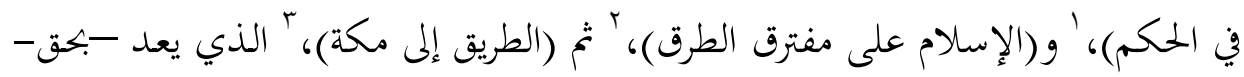

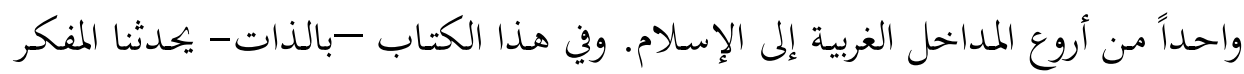

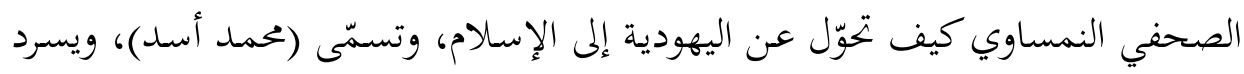

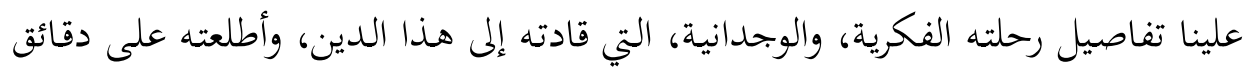
تركيبه المتفرد المعجز .

\section{أولاً: كمال الإسلام وشموله لجوانب الحياة}

يبدأ (فايس) بالتأكيد على أن الإسلام، بتجاوزه حدود العلاقة الفردية بين الإنسان

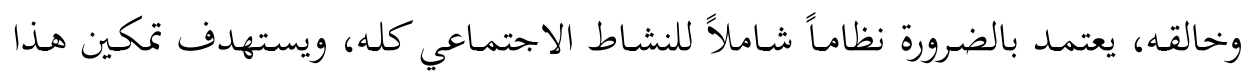

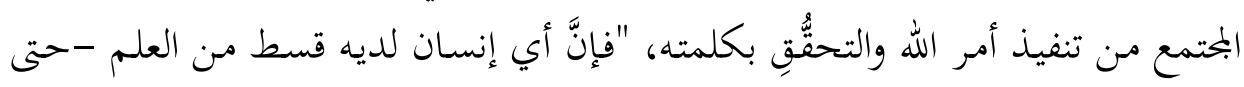

" دكتوراه في التاريخ الإسلاميّ، أستاذ التاريخ والحضارة الإسلامية في جامعة الموصل/ العراق، مفكر وأديب، بريد

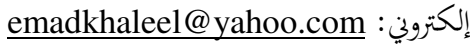
' فايس، ليوبولد، منهاج الإسلام في الحكمم، ترجمة: منصور محمد ماضي، بيروت: دار العلم للملايين، طج،

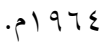

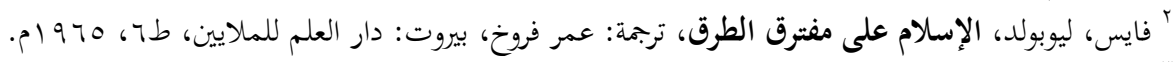

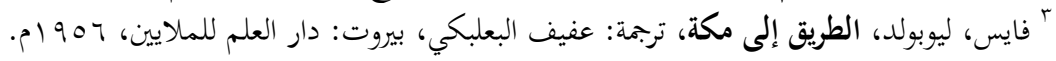


ولو كان سطحياً يسيراً عن تعاليم الإسلام، يعرف أن هذه التعاليم لا تقف عند حد

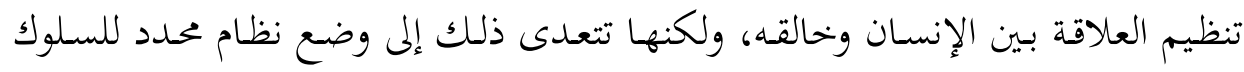
الاجتماعي، يجب على المسلم اتباعه، كأثر من آثار تلك العلاقة، وكنتيجة لما.." إنَّ القـيم الأخلاقيـة الدينيـة المعلقـة في الفضـاء لا تعـني شـيئاً، إذكيـف سـيتاح لهـا

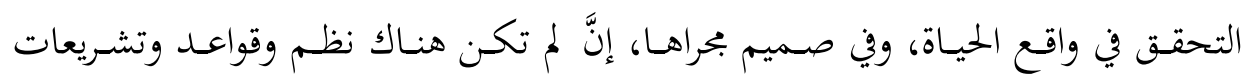
عملية محددة تتولى كبر هذه المهمهة؟ "فالتعاليم المحردة التي نصّت عليها علوم الأخحلاق، كقولم: (أحبب الناس) أو (كن صادقاً) أو (ثق بالله) لا تكفي؛ لأها عرضة لكثير من

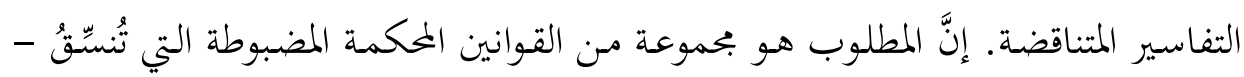
مهما اتسعت دائرة هـا التنسيق - بحال الحياة البشرية بأكمله، وتتعرض لكل مظاهرها

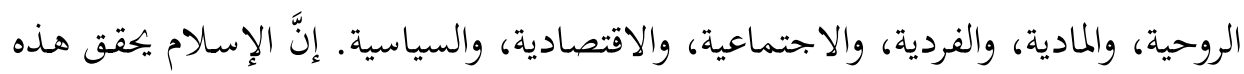
الغاية عن طريق قانون إلهي هو الشريعة، وهي تشمل بين دفتيها الأحكام التي جاء بها

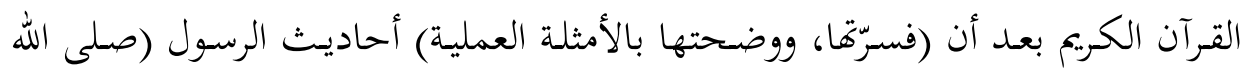
عليه وسلم) التي تسمى السنة."

وهـو يشـير إلى المعادلة المستـحيلة التي حاولـت الأديـان الأخـرى تنفيذها فأخفقـت

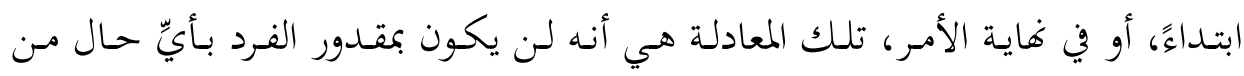

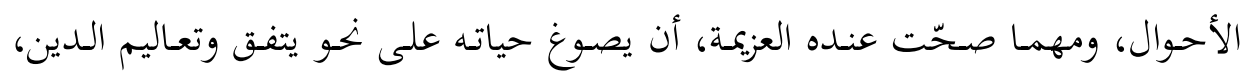

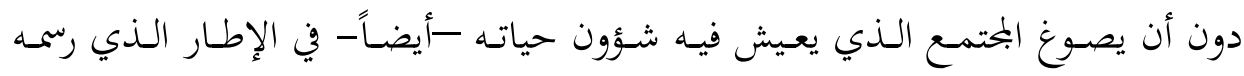
الدين.

ثم مـا يلبـث (فـايس) أن يخلص إلى النتيجـة المحتومـة لهذه المقـدمات كافـة، وهي أنَّ

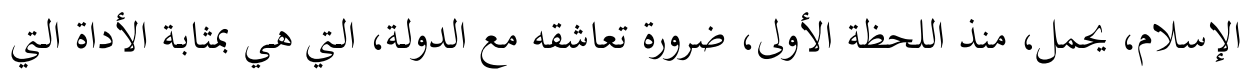

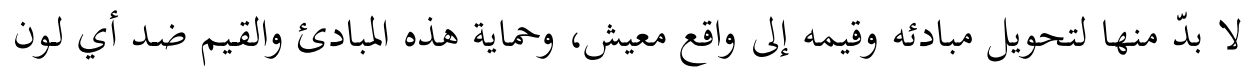

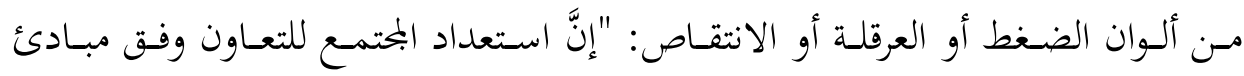

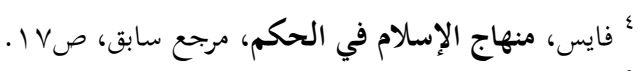

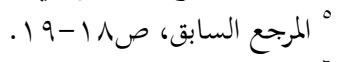

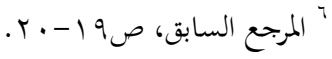


الإسلام لتحقيق غاياته سوف يظل استعداداً نظرياً ما لم تكن هناك سلطة زمنية مسؤولة

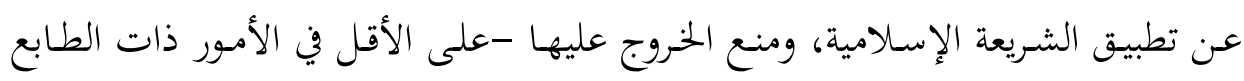

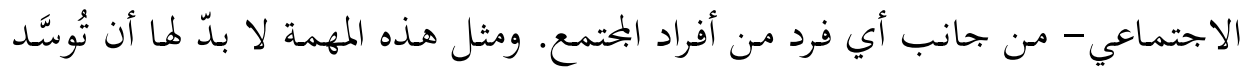

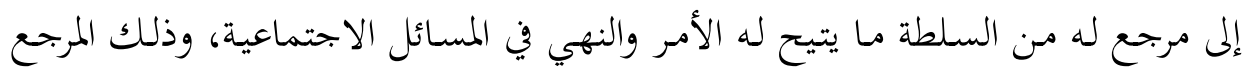
هو الدولة.

ومـن أجـل ألا يـذهب الظـن إلى أنَّ الإسـام، بحكــم هـذه الواقعـة، إنمـا هـو نظـام

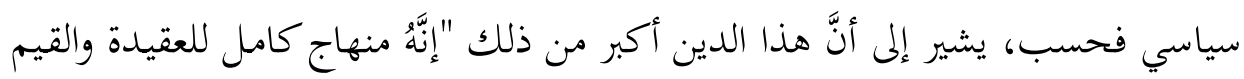

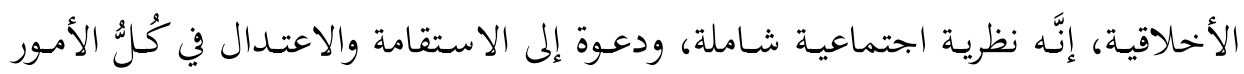

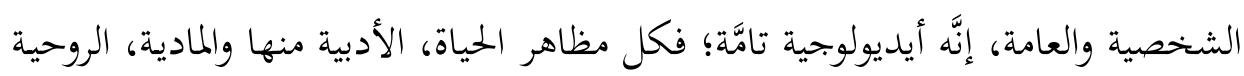

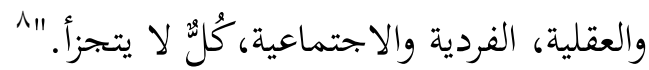

وثمة وَهْمُ آخر قد يتشبث به البعض لهذا السبب أو ذاك، وهو أن شريعة الإسلام قد

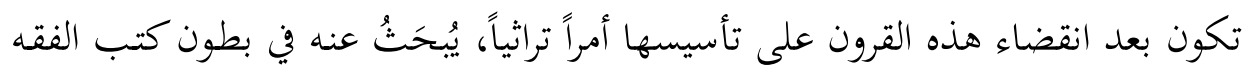

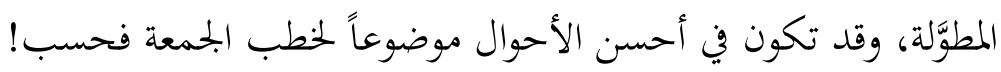
والحـال، كمـا يؤكد (فايس) ليس كذلك بالتأكيـد، فهذه الشريعة هي منهاج حيّ

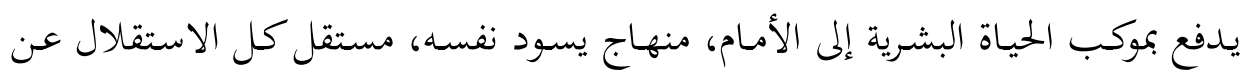

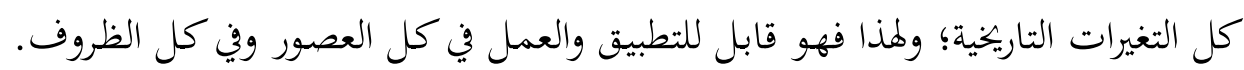

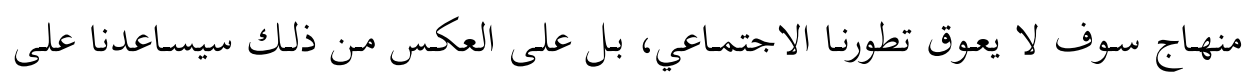

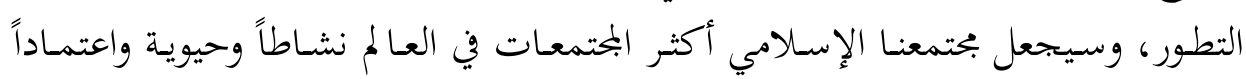
على نفسه.

وبذلك يدحض الرجل الحُجَجَ الواهية لكل أولئك الذين سعوا، لهذا الغرض أو ذاك،

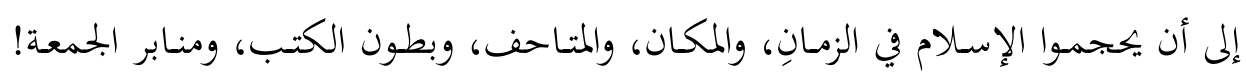
مـا دام أنه، كمـا يعلن عن نفسـه في كل معطياته، منهاج عمل حل حيوي شـامل، يصـلح

$$
\begin{aligned}
& \text { " المرجع السابق، ص • r. }
\end{aligned}
$$

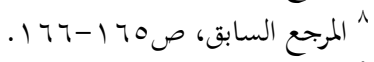

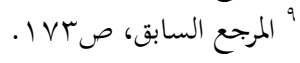


لقيـادة المحتمعـات نحـو الأحسـن والأكفـأ في كل زمـانٍ ومكـان. إنَّهـ كلمـة الله الباقيـة في

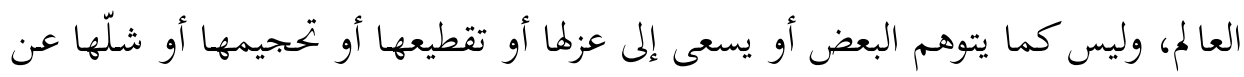
العمل عبر صيرورة الزمانِ والمكان.

هـذا المنهاج يتضـمن، أو يمثل، كُلاً متماسـكاً بسبب مـ تعامله مع سائر طبقات

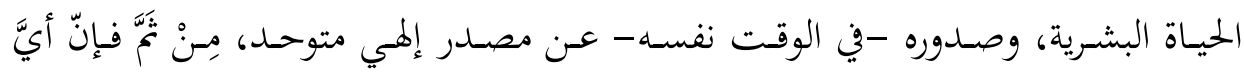

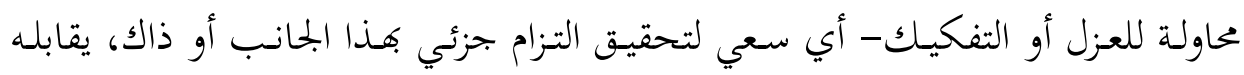

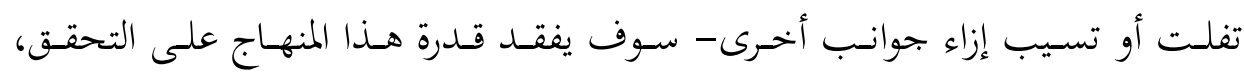

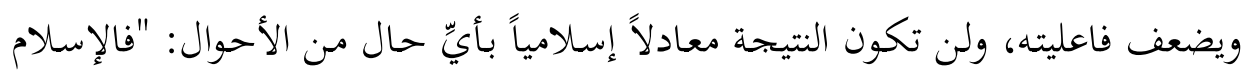

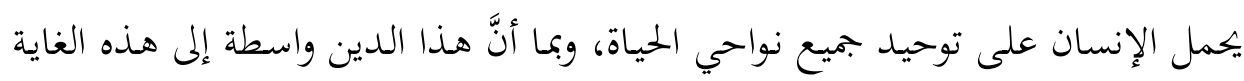

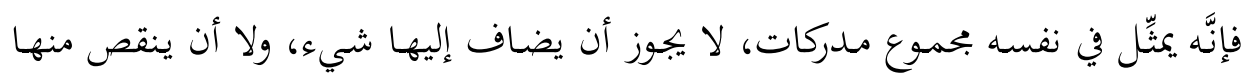

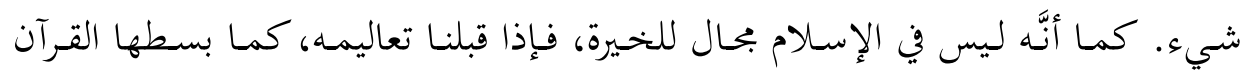
الكريم فعلاً، أو كما أوردها الرسول (صلى الله عليه وسلم)، فيجب علئ علينا أن نقبلها تامَّة

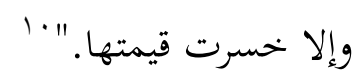
مـن أجـل هـذا التـاخل العميق في بنـاء الشريعة الإسـلامية بـين سـائر المفردات مـن

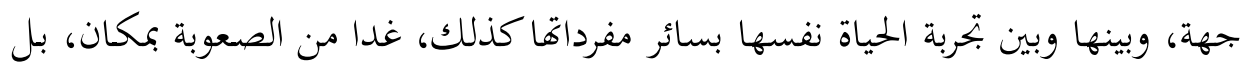

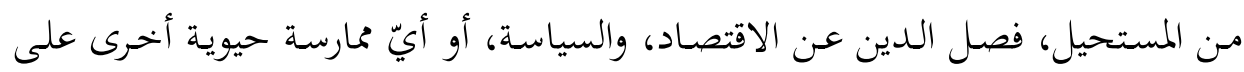

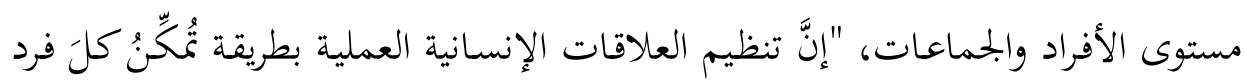

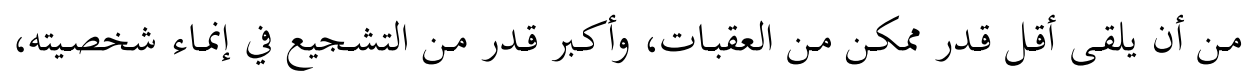

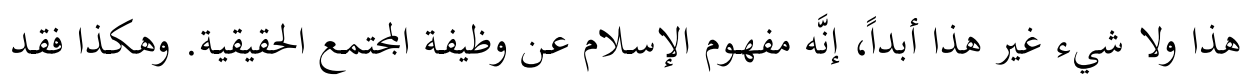

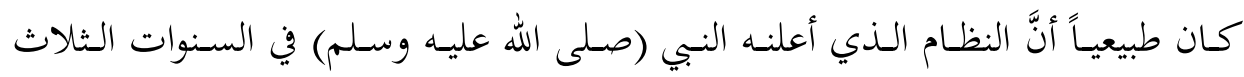

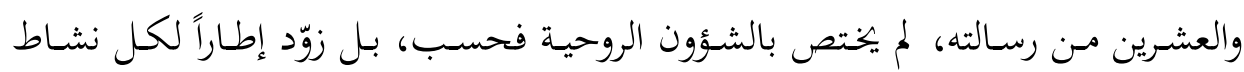

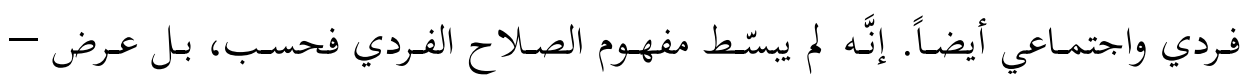
أيضاً- مفهوم المحتمع العادل الذي يجـب أن يوجده ذلك الصـلاح. لقد شنملت الشريعة 
الإسلامية الحياة من جميع وجوهها، المعنوية والجحسدية، الفردية والبحتمعية. وكان لمشاكل

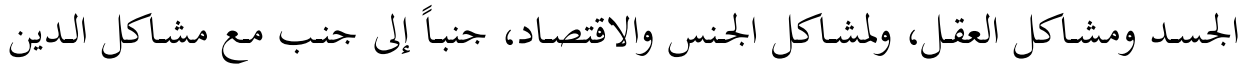

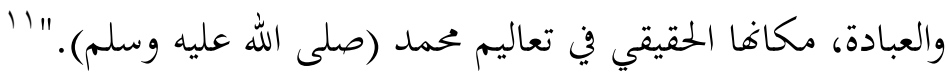

وهكذا، يقول (فايس) وهو يعاين الإسلام من الخارج، بمنظور استشرافي شامل:

"رأيت أمـامي شيئاً يشبه بنـاء هندسياً كاملاً، تُنَمِّم عناصره بعضهها بعضـاً بطريقة

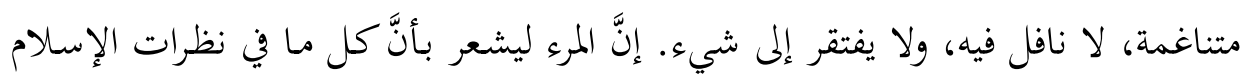
وفروضه هو في محله." وتلك هي -بتركيز بالغ - صورة الإسلام على حقيقته وإعجازه كذلك.

\section{ثانيا: دين التوازن}

لكن الأمر لا يقف عند هذا الحدّ، فإن (فايس) الذي خبر الأديان الأخرى تماماً، وسبر معضلتها الأساسية المتمثلة في أحادية الرؤية ونسبية الموقف الديني، يجد في الإسلام ما يميزه تماماً فيمنحه ضرورة الدوام والاستمرار، بما يتضمنه من توازن عجزت عن التحقق به سائر الأديان والمذاهب.

والرجل يقف عند هذه المسألة الحاسمة طويلاً، فيقلبها على وجوههـا، ويستنطقها

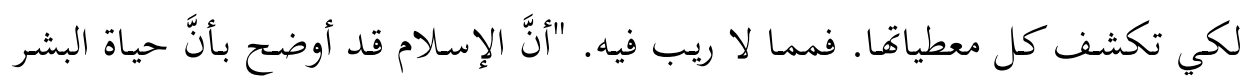

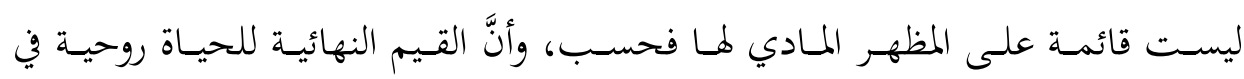
طبيعتها، ولكن على الرغم من ذلك فإنَّهَ لا يحق للمسلمين أنْ ينظروا إلى الحقائق والقيم

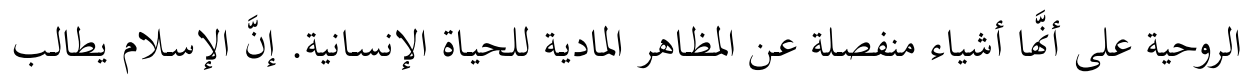

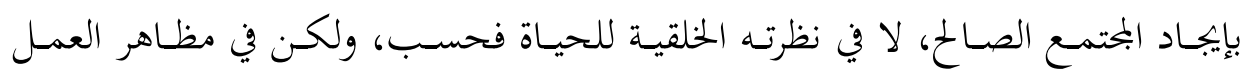

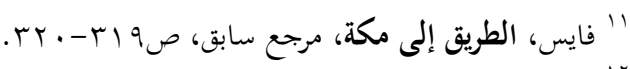

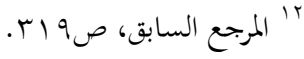


كذلك، بحتمع لا يوفر المطالب الروحية وحدها لأفراده، ولكن يوفر حاجـاتم المعاشية

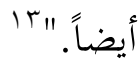

هكـذا، ومنـــ البـدء، يلحظظ الرجـل هـــا التـوازن في المنظـور الإسـلامي بـين سـائر الثنائيات: القيم الروحية والمظاهر المادية، النظرة الخلقية ومظاهر العمل، المطالب المعنوية

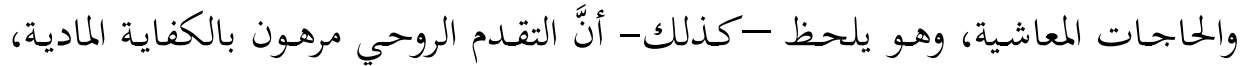

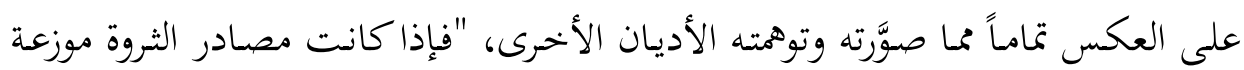
توزيعاً لا عدالة فيه، بحيث يتمتع البعض بعيش رغيد، بينما تناضل الأكثرية بكل قواهـا

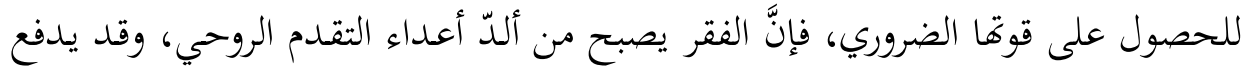

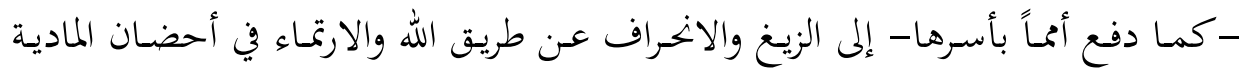

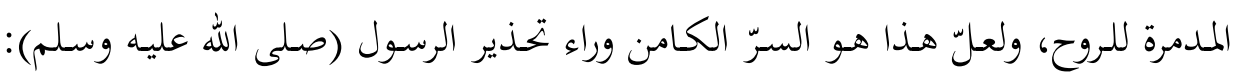

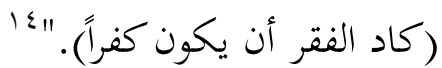

يوغل (فايس) وهو يتابع معطيات التوازن في نسيج الإسلام، فيشير إلى أن الإسلام،

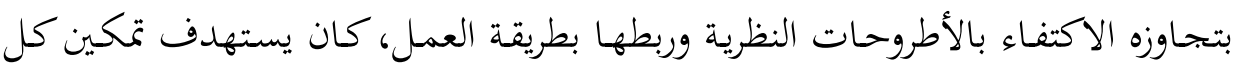
فرد "في نطاق حياته الدنيويـة أن يعيد وحـدة الفكر والعمل في وجـوده ووعيـه كليهمـا. وللوصول إلى هذا الهدف السـامي في الحياة، كان الإنسان في الإسالام غير بحبر على أن يرفض الدنيا، وليس ثمة حاجة إلى تقشف يفتح عليه باباً سريّاً إلى التطهير الروحي. ذلك

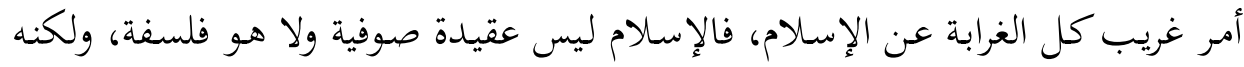
هج من الحياة حسب قوانين الطبيعة التي سنها الله لخلقه، وما عمله الأسمى سوى التوفيق

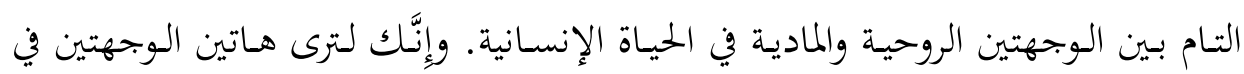

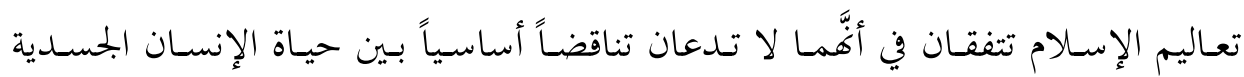

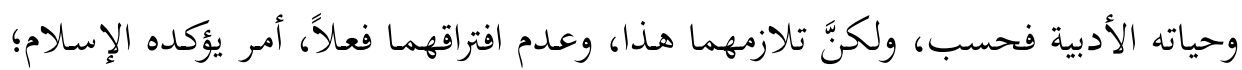

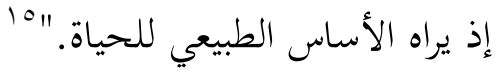

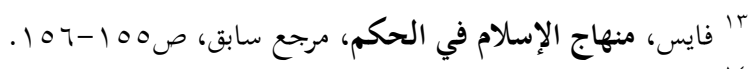

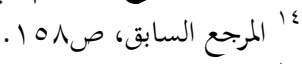

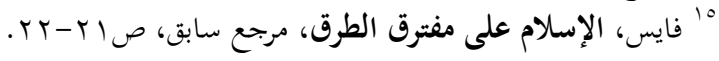


وكما هو الحال بين النظرية والتطبيق، فإن التأكيد الإسلامي ينصبّ بالقوة نفسها،

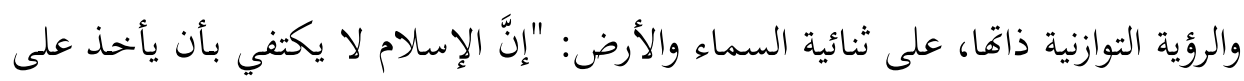

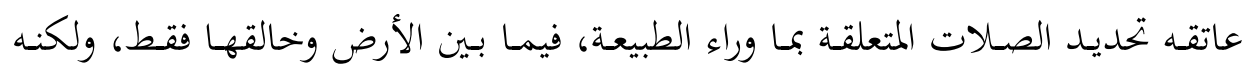

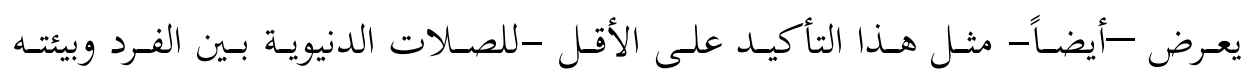

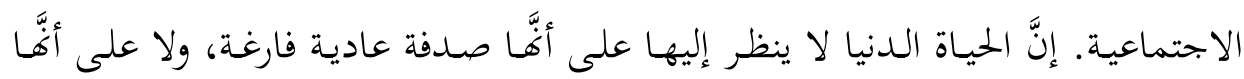
طيف خيال للآخرة، التي هي آتية لا ريب فيها من غير أن تكون منطوية على معنى ما، إلى إلى

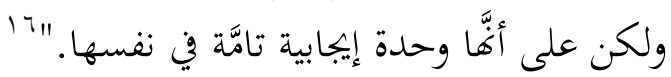

والحياة الدنيا هذه إنَّا هي فرصـة لتحقيق الذات، ليس بـالنفي أو الانفصال، كما

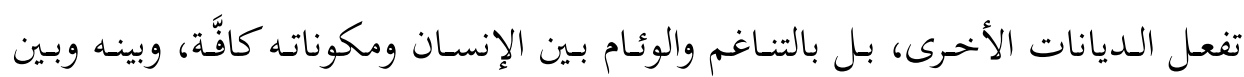

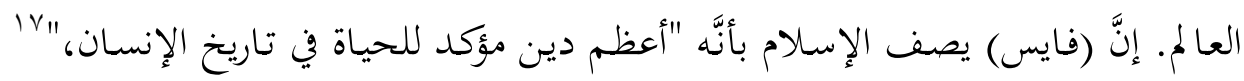

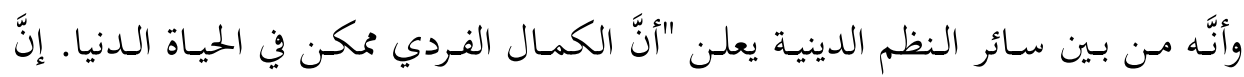

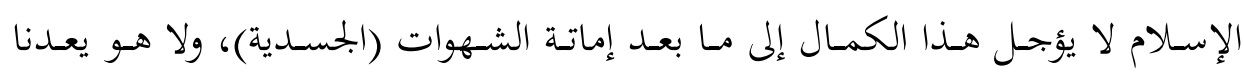

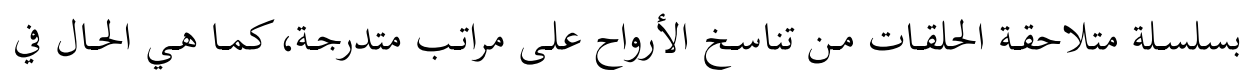
الهندوكية، ولا هو يوافق البوذية التي تقول بأن الكمال والنجاة لا يتمان إلا بعد العهد العدام النفس الجزئية وانفصام علاقاها الشعورية من العالم. كلا! إنَّ الإسلام يؤكد في إعلانه أَََّّ

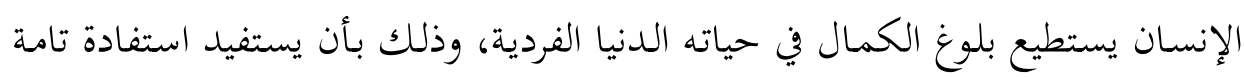

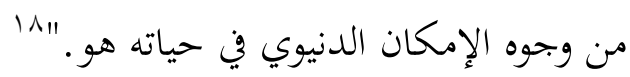

من أجل ذلك ترك الإسلام الطريق مفتوحاً لكل إنسان كي يمارس التحقق الذاتي،

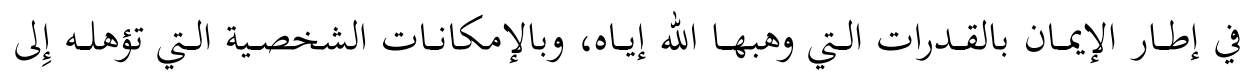

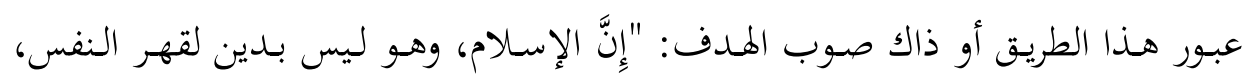
يترك للإنسان بحالاً واسعاً في حياته الشخصية والاجتماعية، كيما تستطيع تلك الصفات المختلفـة، مـن العواطف والميول النفسـانية، أن بتحد سبيلها في التطور الإيجابي المتفق مـع

$$
\begin{aligned}
& \text { 14 المرجع السابق، صع ب. }
\end{aligned}
$$

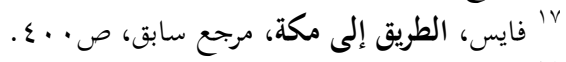

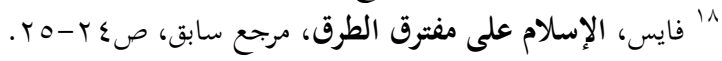




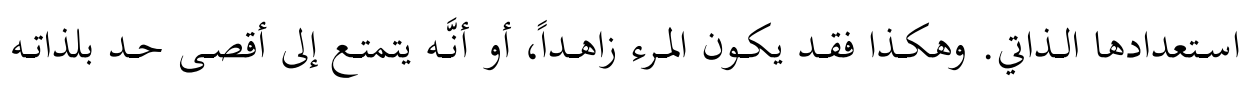

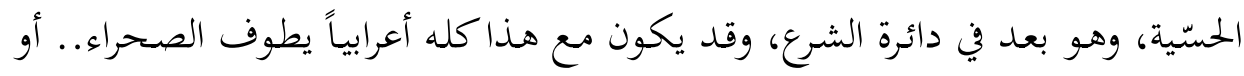

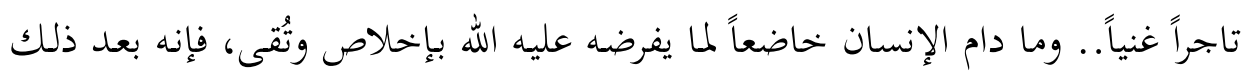
حُرُّ في أن يكيف حياته الشخصية على الشكل الذي توجهه إليه طبيعته. إنَّ واجبه أن وأن يستخرج من نفسه أحسن ما فيها؛ كيما يشرف هبة الحياة التي أنعم الله عليه بها، وكيما

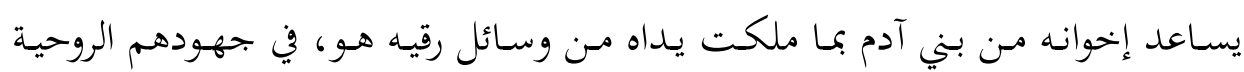
والاجتماعية والمادية. على أن شكل هذه الحياة الشخصية ليس بحال مقيداً بقياس مـا.

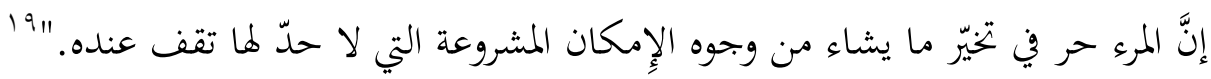
إنَّ هذا التوازن المرسوم بين الإنسان والعالم، يمكن أن يقودنا إلى قيمة أساسية أخرى

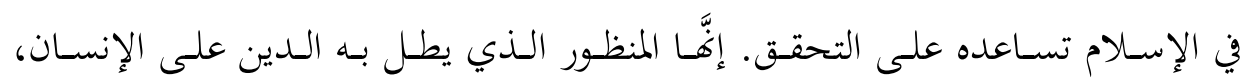

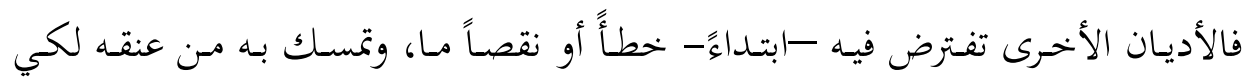

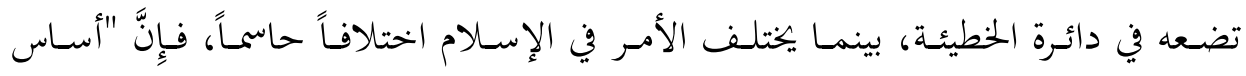
(حرية) الاختيـار في الإسلام يقوم على الافتراض بـأنَّ الأصل في طبيعة الإنسان الخـير.

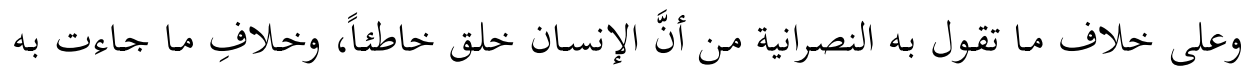

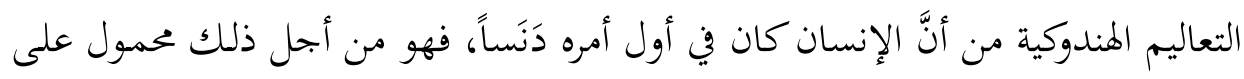
أن يتخبط في سلسلة من التقمص نحو هدفه الأقصى من الكمال، نرى تعاليم الإسلام

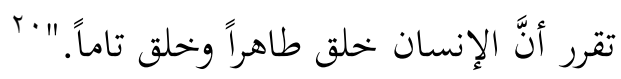

ومعنى هذا أنَّ الإسلام وحده، من بين سائر الأديان "يتيح للإنسان أن يتمتع بحياته الدنيا إلى أقصى حدِّ، من غير أن يضيع ابتحاهه الروحي دقيقة واحدة. وهذا يختلف كثيراً عن وجهة النظر النصرانية. حيث يتعثر (الإنسان) في الخطيئة الموروثة التي ارتكبها آدم

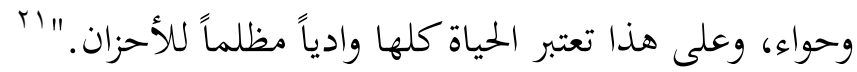




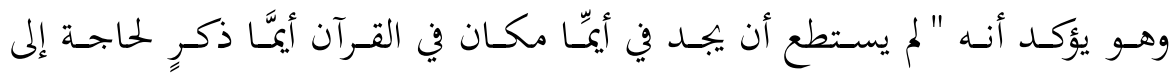
(الخلاص) ما دام أنَّهّ ليس هناك في الإسلام خطيئة (أولى) موروثة تقف بين الفرد ومصيره

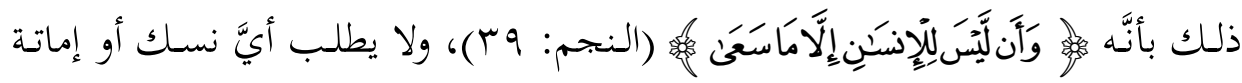

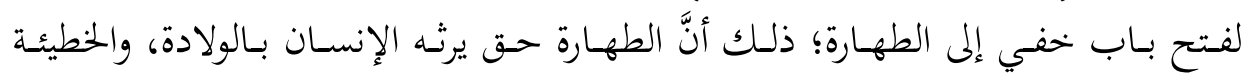

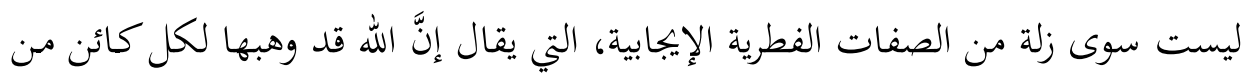

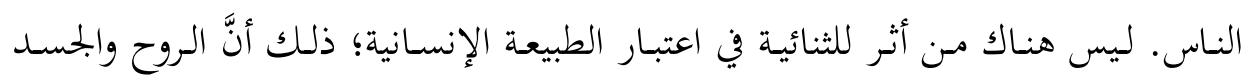

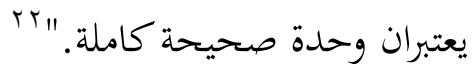

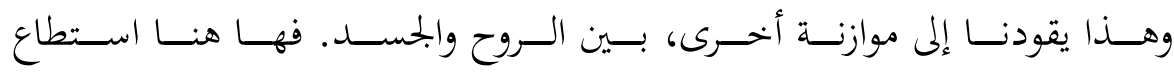
الإسـلام، حيث عجزت سائر النظم والأديان، عن تحقيق هـا الوئام بين قطبي النسيج الآدمي، على جعلهمـا يلتقيـان ويعطيـان وفـق خطـوط متعاشـقة متوازيـة، لا متصـادمة

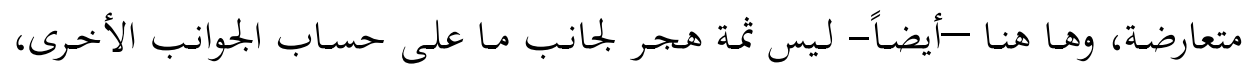
الأمر الذي يمنح الإنسان على المستوى النفسي -وقد بحاوز نقطة الشدّ والجلذبـ- توحداً واطمئناناً، ويمنح الجماعة على المستوى الحضاري قدرة أكثر على الفاعلية والعطاء. "لقد بدا لي أن معالجة (الإسلام) مشاكل الروح أعمق جداً من معالجة العهد القديم، ولم تكن

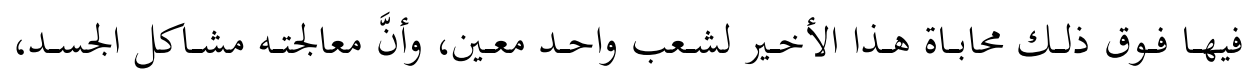

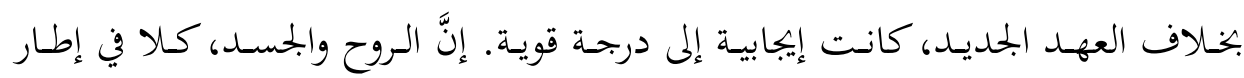

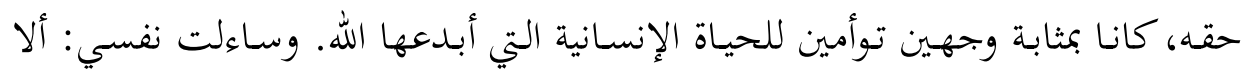
يمكن أن تكون هذه التعاليم مسؤولة عن الأمن العاطفي الذي أحسسته، كل تلك المدة

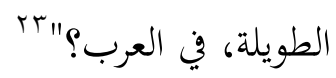

ومع هذا الموازنات الفذة بين الإنسان وذاته، بينه وبين العالم، وبين الأرض والسماء، بـين الرووح والجسـد، هنـاك تـوازن آخـر بـين الـدين والعقـل، وبينـه وبـين التقـدم العلمي.

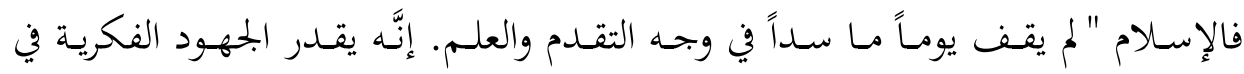

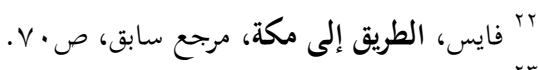

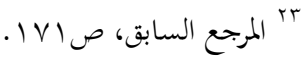


الإنسان إلى درجة يرفعه فيها فوق الملائكة. وما من دين ذهب إلى أبعد من الإسلام في

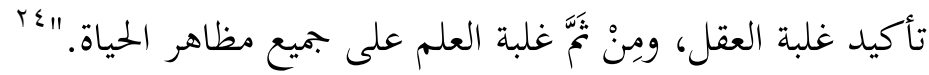

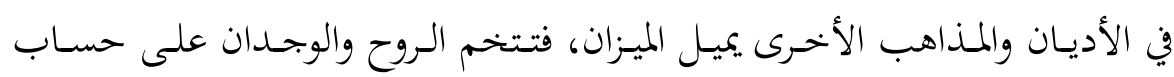

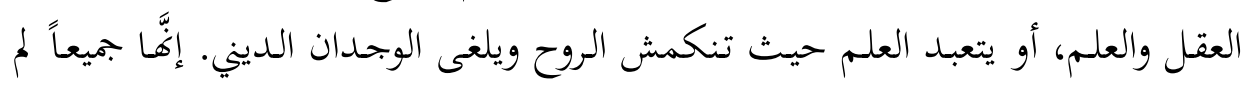

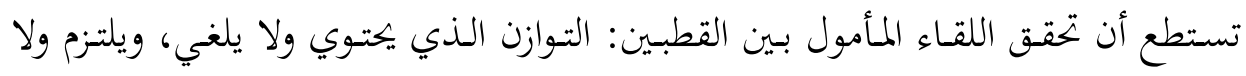

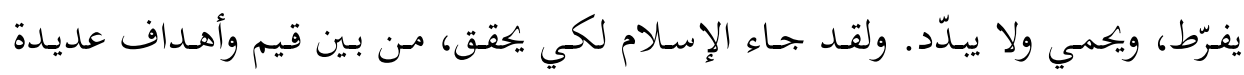

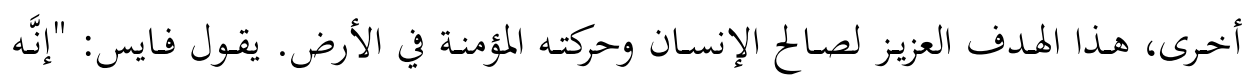

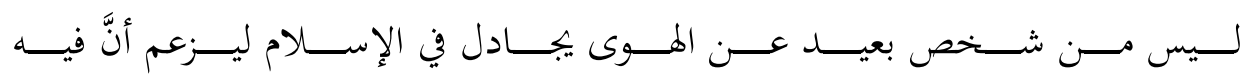

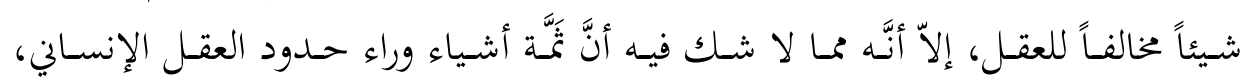

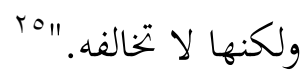

وتلك هي المعادلة الصعبة التي قـر الإسـلام على حلها: أن بتعل البنيـان الديني منسجماً مع معطيات العقل، رغـم أنه في الأساس ينبثق عمـا وراء حـدود العقل، قادماً

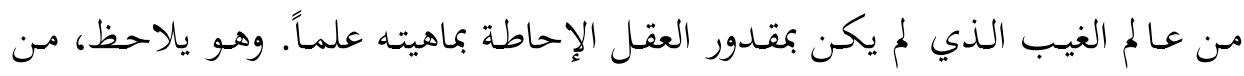

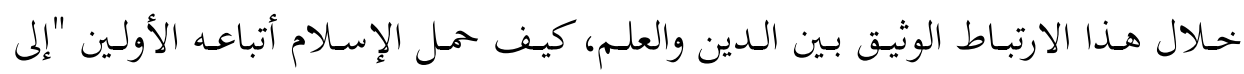
أعـالي الذروات الثقافيـة بتوجيه طاقاتم كلها نحو التفكير الواعي بوصفِهِ وسيلة وحيدة

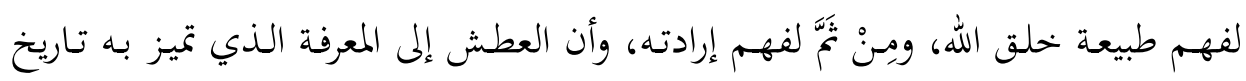

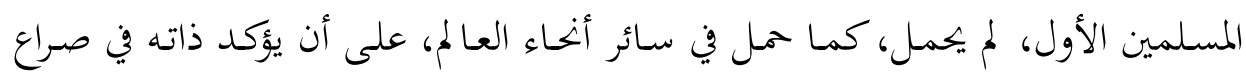

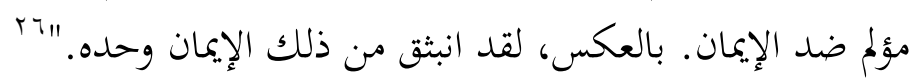

والحق أنَّ هذا المنظور التوازني في الإسلام، وهذا المعمار المتفرد الذي يضـم جناحيه على سائر الثنائيات فيضعها في مكاها الصحيح، ويحقق بينها التصالح والتناغم والألفة

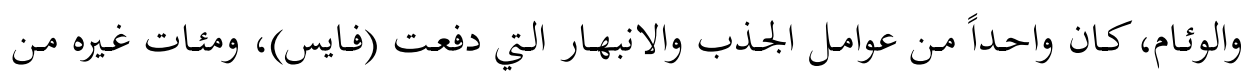

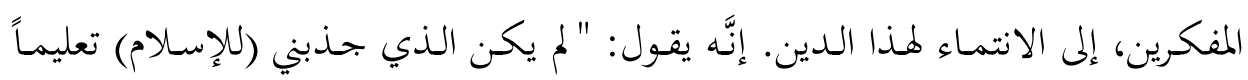

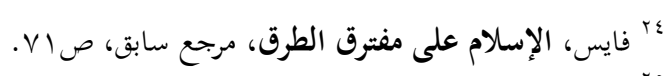

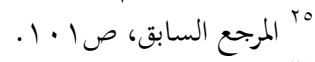

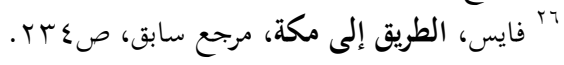


خاصاً من التعاليم، بل ذلك البناء البمموع العجيب والمتراص بما لا نستطيع له تفسيراً من تلك التعاليم الأخلاقية، بالإضـافة إلى منهاج الحياة العملية. ولا أستطيع اليوم أن أقول

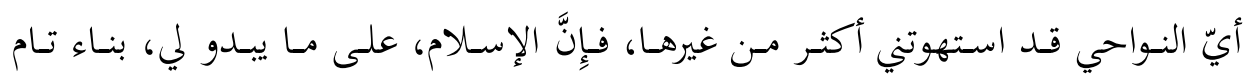

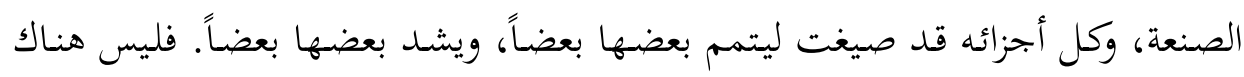
شيء لا حاجة إليه، وليس هنالك نقص في شيء، فنتج عن ذلك كله ائتلاف مرصوص.

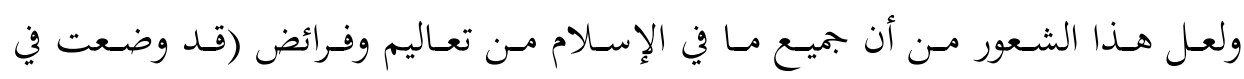
مواضعها) هو الذي كان له أقوى الأثر في نفسي."rV"

\section{ثالثاً: دين المرونة في التشريع}

هنالـك، مـع الشـمولية والتـوازن، خحاصـية أخــى لا تقـل أهميـة وفاعليـة في الحيـاة الإسلامية، بل ربما أنه بسببها قدر الإسلام على أن يواصل طريقه في صميم الحياة بالقوة

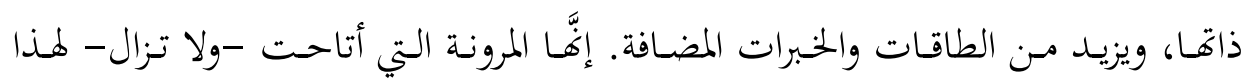

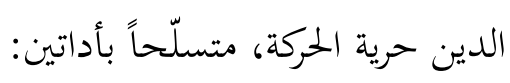

أولاهما: المبادئ الأساسية الثابتة التي تحمي شخصيته وتميزه؛ ذلك أنَّ الشريعة، في أساسها، "لا يمكـن تغييرهـا؛ لأنها نـاموس إلهي، بـل إنه ليست هنـاك ضـرورة تـدعو إلى تغييرهـا؛ لأنَّ كـل أحكامهـا صـيغت بكيـث لا يتعـارض أحسدها مــع الطبيعـة الأصـيلة

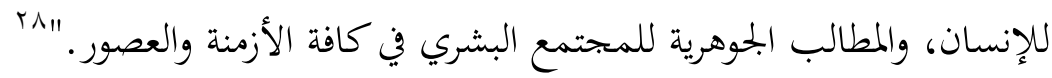
أما ثاني هاتين الأداتين فهي: المساحات المفتوحة الحرة للاجتهاد، والإضافة، وبحابهة المتغيرات، والاستجابة للتحديات، تلك التي تُمُكنه من التواصل الدائم مع حركة الحياة، وتغطيتها أفقياً وعمقياً، وِمنْ ثَمَّ قطع الطريق على أيِّ محاولة للعزل أو التجميد، وإعـادة الإنسان ثانية إلى مآسي الثنائيات التي أسرته طويلاً. 
إنَّ (فايس) يلحظ منذ البدء، كيف "أنَّ الأحكام السياسية الإسلامية القائمة على القرآن والسنة (ليست) واضحة، ثابتة الدعائم فحسب، ولكنَّها لا تعاني من آفة الجمود

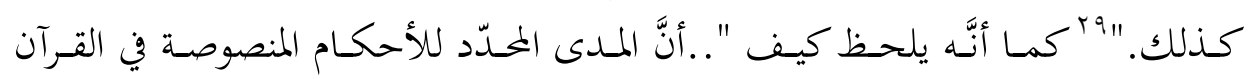
والسنة، لم يكن نتيجة سهو وقع من الشارع، ولكن على العكس، لقد أراد به أن يكون

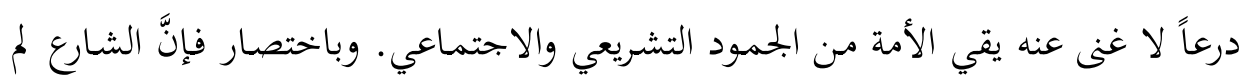

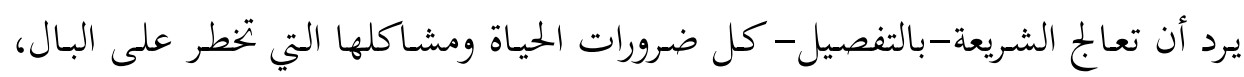

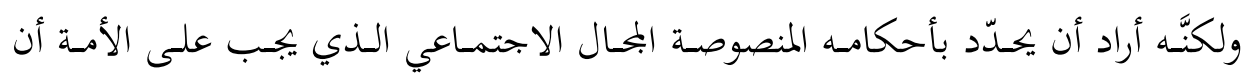
تتطور في حدوده، وترك هذا العدد الهائل من المسائل القانونية المحتملة الوقوع لتعالج كل

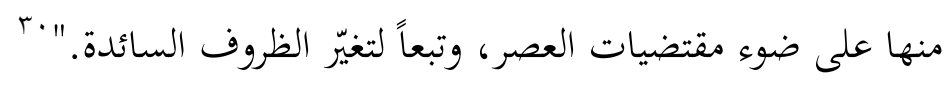

وهـو يلحظظ المسـألة كلهـا بمـا يؤكسد دور المسـلم نفسـهـ في صسياغة الحيـاة، أو إعـادة صياغتها، في الإطار الإيماني المرتحى، وعلى هـدى التعاليم والقيم الأساسية لهذا الدين:

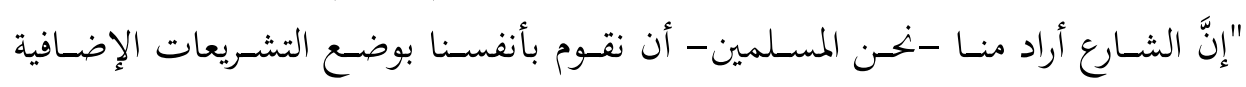
الضرورية عن طريق اجتهادنا، أي عن طريق التحليل العقلي المستقل، بشرط أن يكون

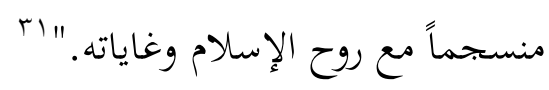

وثمة رأي يؤكده (فايس) في أكثر من مكان، في سياق معطياته عن المرونة التشريعية،

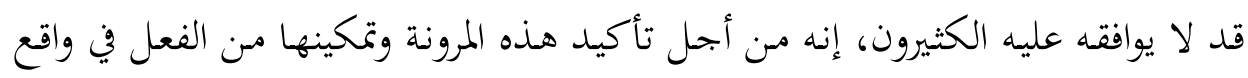

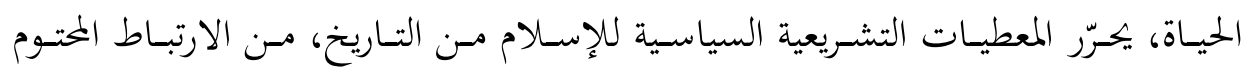

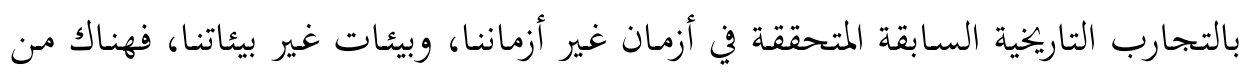

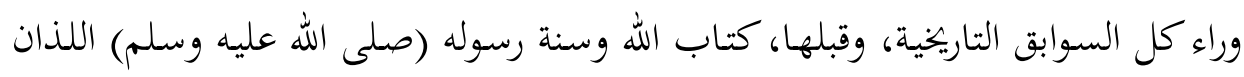

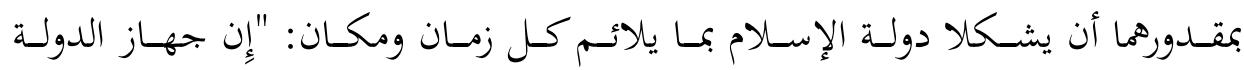

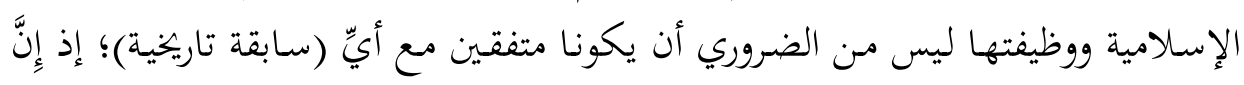

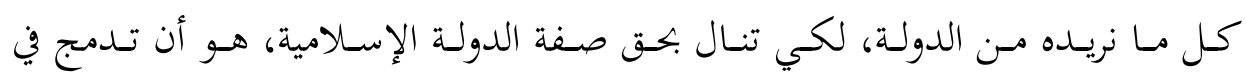
دستورها، وأن تستهلدي في أعمالها، تلك الأحكام الظاهرة المنصوصة في القرآن والسنة، لنكا،

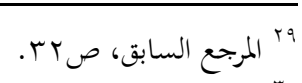

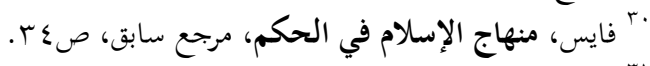

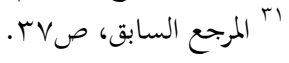




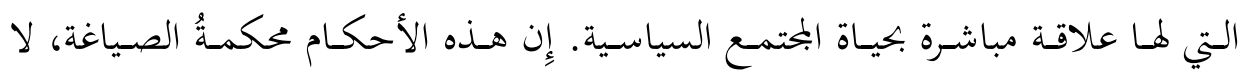
يلابسها غموض، ولكنها -بلا استثناء- ذات طبيعة مرنة، تسمح لها بالحياة والعمل في

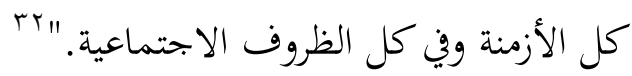

و (فايس) انطلاقاً مـن خلود الرسالة الإسلامية وديمومتها، يضع يده على الأسباب التي جعلت للعقل الإنساني، والكشوف التي تتمخض عن نشاطه، هـا المـدى الواسع الذي يتحرك عبره، مستفيداً أكثر فأكثر من الخبرات الجلديدة، مرتبطاً - في الوقت نفسهـبمحــاوره الثابتـة في القـرآن والسـنة: "إن علينـا ألاّ ننسـى أبــاً أن رسـالة الإسـلام رسـالة خالدة، وأهـا -لـذلك- يجـب أن تظل مفتوحـة أمـام العقل الإنسـاني الذي لا يَكلهُ عن

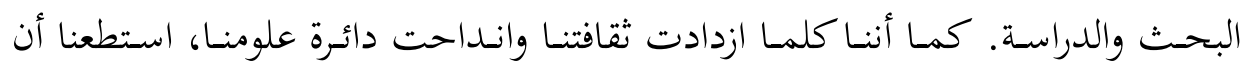
نفهـم بصورة أوضح من ذي قبل كنوز الحكمة التي ينطوي عليها القرآن، وأسوة الرسول

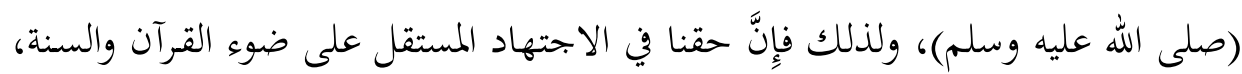
ليس مسموحاً به فحسب، بـل نحن منتدبون لأداته في كل الأمور التي اكتفت الشريعة

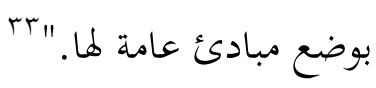

وهكذا نـركك كيف أن مرور الزمن وتراكم الخبرات البشرية يمكن أن يكونـا لصـالح

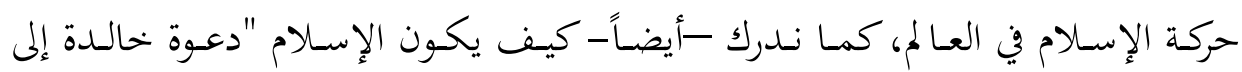

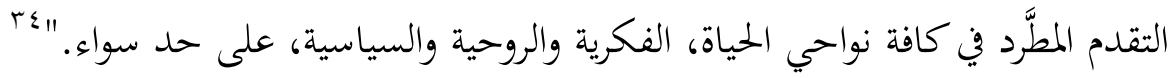

\section{رابعاً: آفاق العبادة في الإسلام}

وكمـا أنَّ (فايس) يتحـلث عن خصـائص التشـريع الإسـلاميّ، الذي يمثل مسـاحة

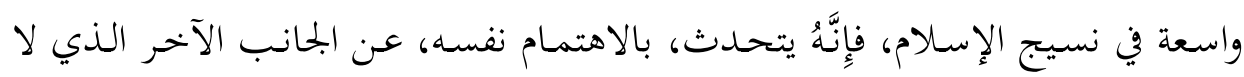
يقل أهمية؛ لأنه يمثل عصب الحياة الإسلامية، وروحها المحركة، وشعارها: العبادة. 
هذا على افتراض أنَّ التشريع يمثل جانباً، والعبادة تمثل جانباً آخر في بنيان الإسلام، والحال أنَّ التشريع والعبادة معاً، مضافاً إليهما الأخحلاق وآداب السلوك والمعاملة، فسائر

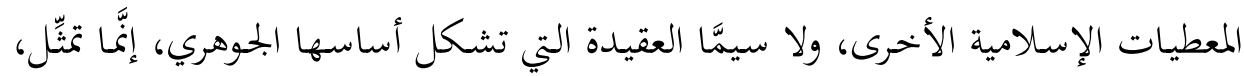

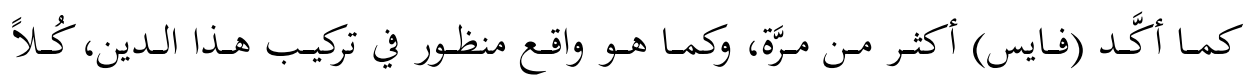

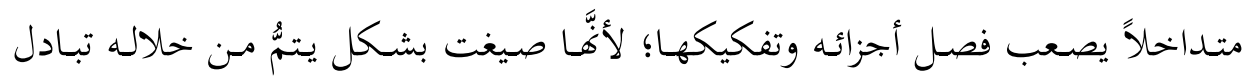
التأثر والتأثير؛ إذ الجميع يخفق بإيقاع متوحد، ويتلقى دمه النقيّ الحار من مصدر واحد. مـا الذي يقولُهُ الرجل عن ممارسات تعبّدية، كالصلاة والزكاة والصوم والحهج، وهـو

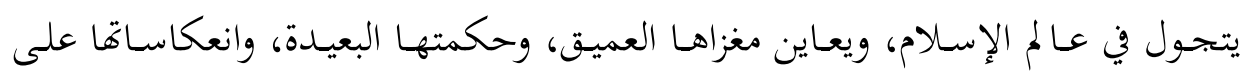

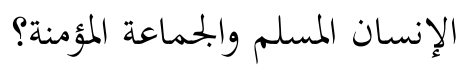

إنَّهَ يؤكد، منذ البداية، الطابع الشمولي للعبادة الإسلامية، حيث تغدو كل ممارسة،

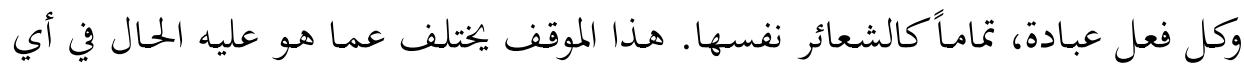

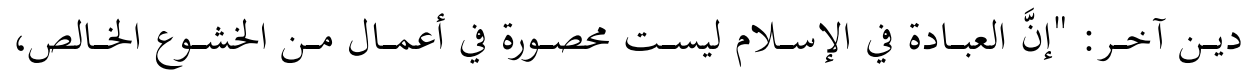

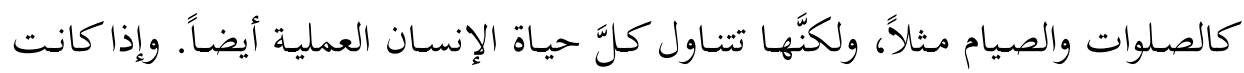

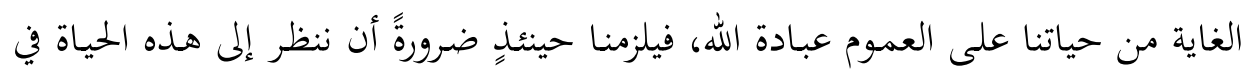

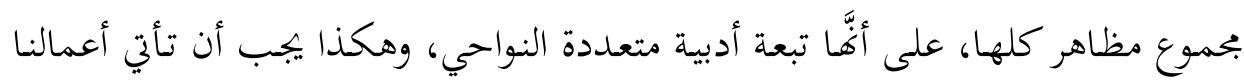

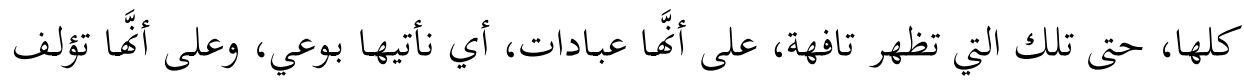
جزءاً من ذلك المنهاج العالمي الذي أبدعه الله."

إنَّ هذه الرؤية بمداها الشاسع هذا، تنبثق ولا ريب، أو إفَّا تمثل امتداداً للخصائص الأساسية التي مرت بنا في المقاطع السابقة: الشمولية والتوازن، والمرونة.

فبإنَّ العبادة الإسلامية فضالًا عن كوهـا تطوي جناحيها على كل صغيرة وكبيرة في

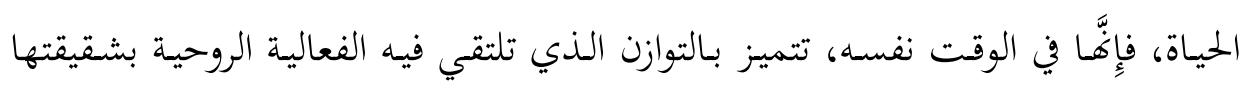

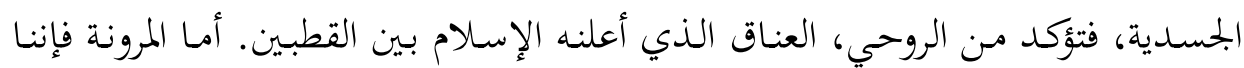

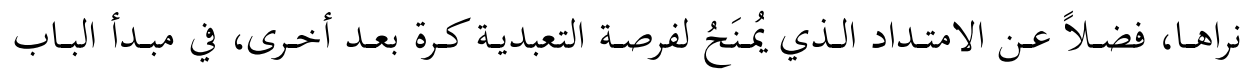




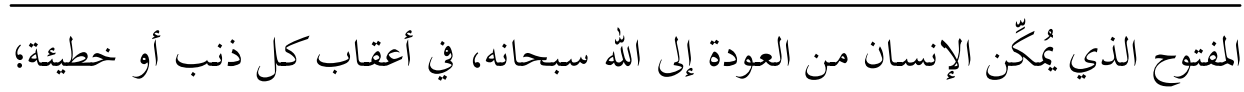

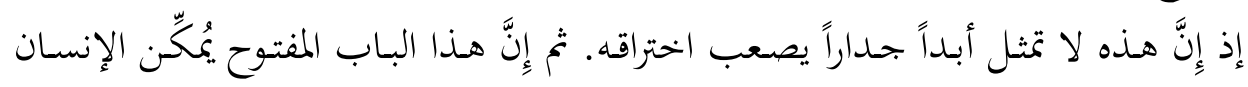
المسلم -من جهة أخرى- من الذهاب مباشرة إلى الله، من جعل الممارسة التعبدية لقاءً

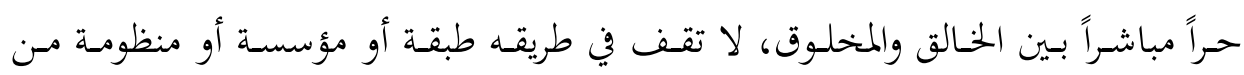

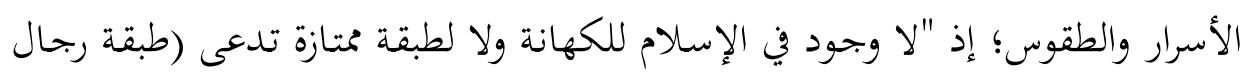

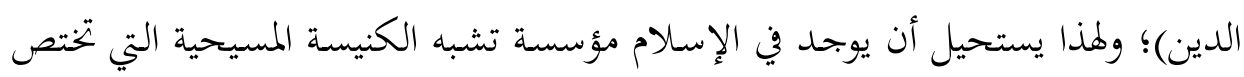

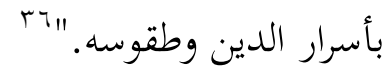

بعـدها يتحـدث (فـايس) عـن الشعائر الإسـلامية المحلددة المتميـزة التي تمثـل نقـاط

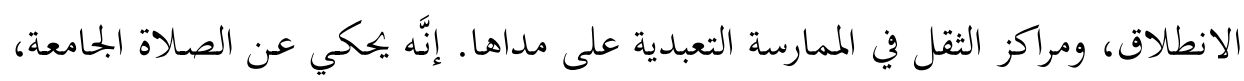
فيرى "أَنَّ هناك أشياء قليلة، هذا إذا وجدات، تقرب بين الناس كما تقرب بينهم الصلاة

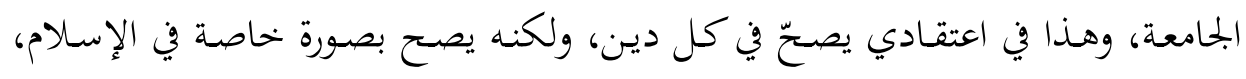
الذي يرتكز إلى الاعتقاد بأنَّه ليس من واسطة ضرورية، أو بالأحرى ممكنة، بين الإنسان

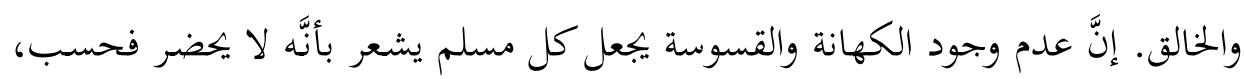
بل يشارك مشاركة صادقة في فعل العبادة المشترك عندما يصلي جماعة. ويتحـدث عن الصـيام فيرى أنَّ "الغاية منـه غايـة مزدوجـة. إنَّ على الفـرد، أولاً، أن يمتنع عن تناول الطعام والشراب حتى يشعر في جسمه هو بما يشعر به الفقراء والجائعون،

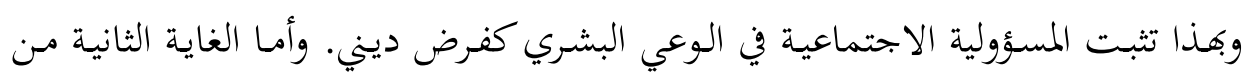
الصيام فهي ضبط النفس، وهي ناحية من نواحي أخحلاق الفرد التي تشدد عليها التعاليم الإسلامية جميعاً (كما في التحريم الكلي، مثلاً، للمسكرات التي يعتبر الإسلام أها سبيل

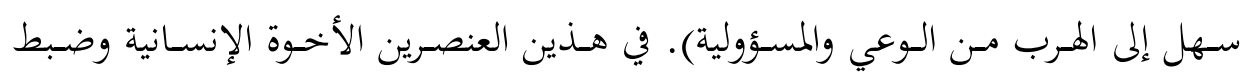

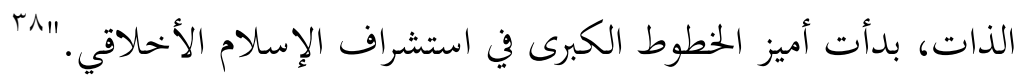

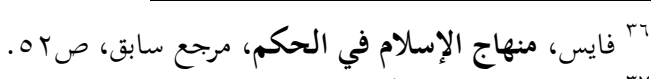

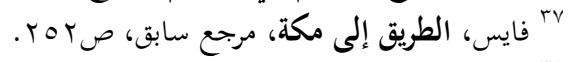

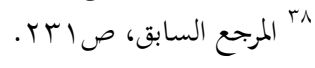


ويقف عند فريضة الحج مبهوراً، فيجد كيف أنَّا "إذا درنا حول شيء ما، فإنَّا نقرر

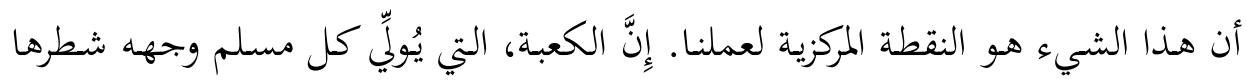

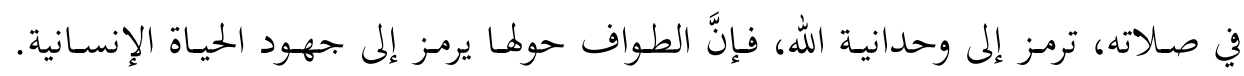

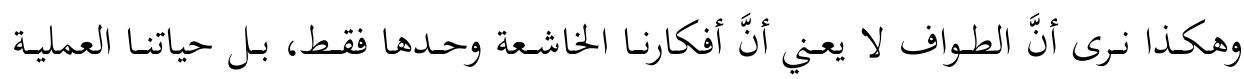
وأعمالنا وجهودنا أيضاً، كل هذه يجب أن تتمثل في نفسها فكرة الله ووحدانيته على أفها

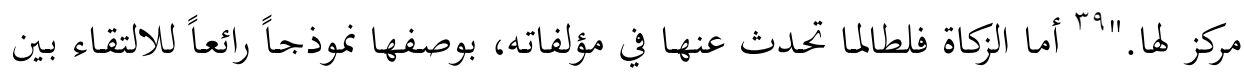

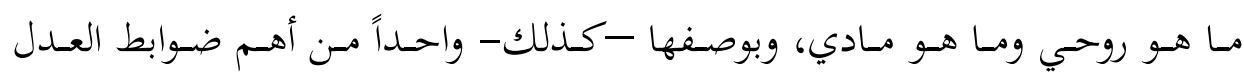
الاجتماعي في الإسلام.

\section{خامساً: دين المبادئ والقيم الحضارية}

نتابع (فايس) وهو يضع يده على أهداف المجتمع الذي يصوغه هذا الدين، وطبيعة

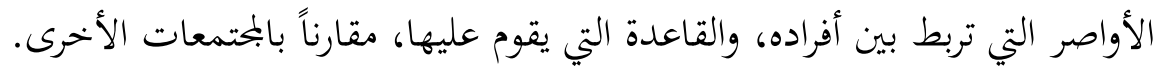
إنَّه يستنتج ابتداءً "أَنَّ المحتمع الإسلامي ليس في ذاته غاية، ولكنه وسيلة إلى غاية.

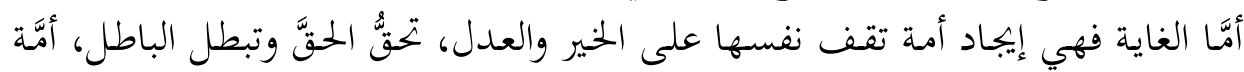

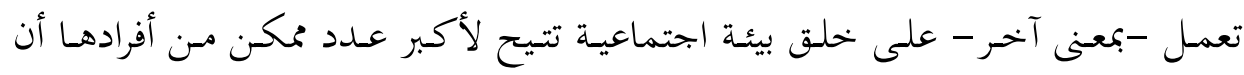

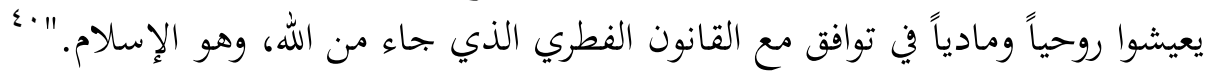
أمـا الرابطة التي تشـد أعضـاء هـذا المحتمع، وتمسـك بـه فهي "الاشـتراك في العقيـدة

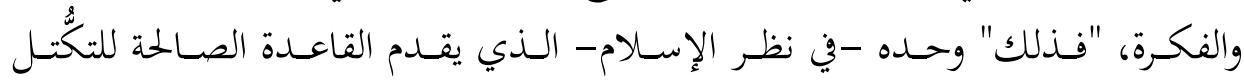

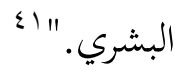

وأمـا الوسيلة، أو الأداة، التي تُّكِّن هـا المجتمع العقائدي مـن أداء مهمتـه في العالم

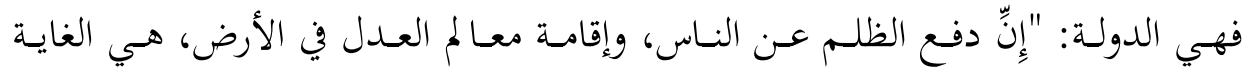

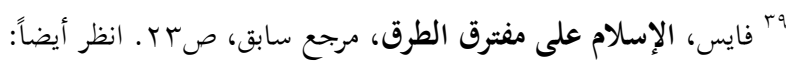

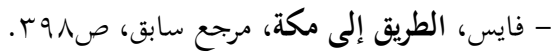

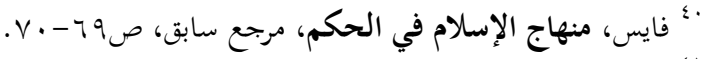

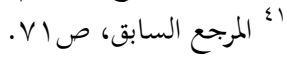


النهائية التي تستهدفها رسالة الإسلام الاجتماعية. وعلى هذا المثل الأعلى للعدالة -مع المسلمين وغير المسلمين على حد سواء- يتوقف قيام الدولة الإسلامية وسقوطها. هذه الدولة التي ليست هي في الحقيقة سوى الجهاز السياسي لتحقيق هذا المثل الأعلى. "rاء وأمَّا خصائص هذا المجتمع فيمكنُ أن تتمحور في اثنتين: المساواة، والفاعلية: "لقد صيغت جميع مواد الشريعة الإسلامية لصالح أعضاء المُتمع كلهم بالتساوي دون تمييز بين

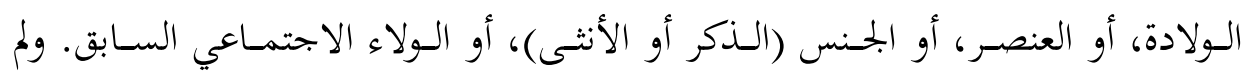

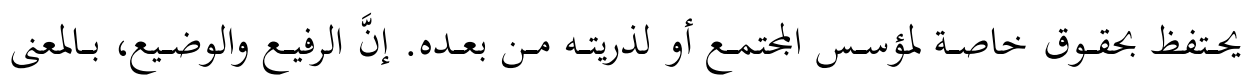

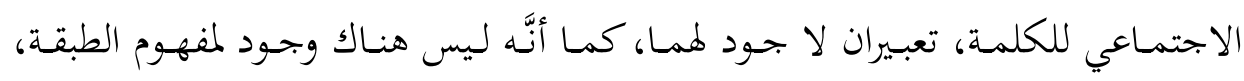

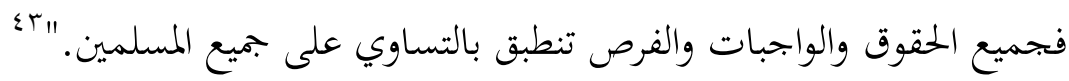
وقـد يخطر على البـال هـا هنـا أنَّ الإسـلام والمسيحية قد كان لمما الهـدف نفسـه:

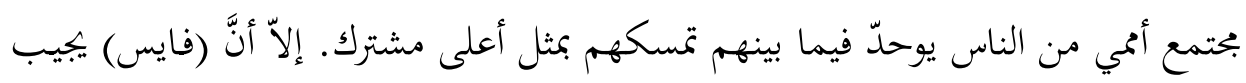

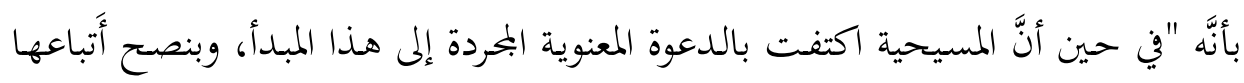

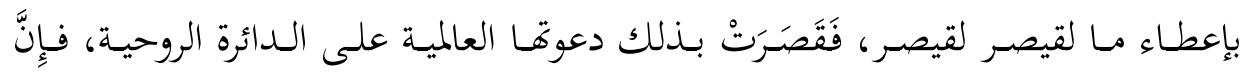
الإسلام قد كشف للعالم عن مؤسسة سياسية، يكون فيها وعي الله الباعث على سلوك

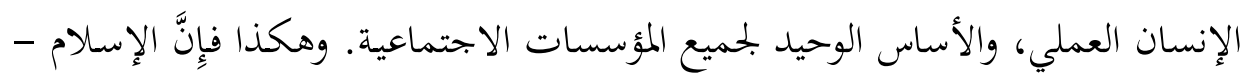

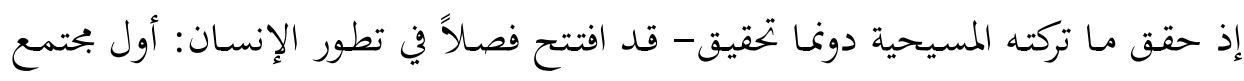

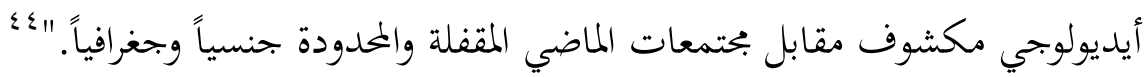

يمضي (فايس)، بعـد أن أوضـح الفروق الحاسمـة بين المختمعين الإسـلامي والمسيحي

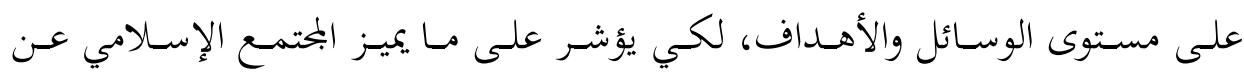

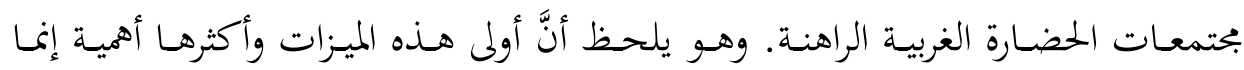

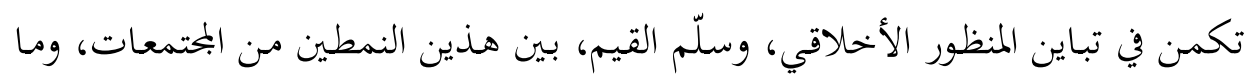
نتج عن ذلك من أفعال وممارسات: "نحن نعتقد، والتطور الحمديث في الغرب يثبت هذا

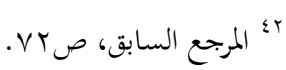

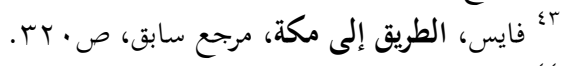

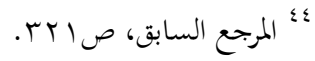


الاعتقـاد أيضـاً، بــأنَّ الأخهاق في الإسـلام، وخصوصـاً في إدراكهـا للسـلوك الاجتمـاعي

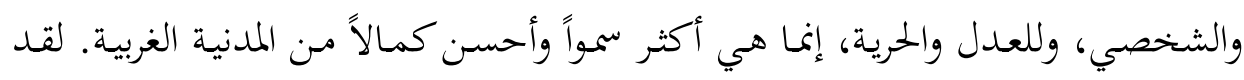
أبطل الإسـلام العصبية العرقية (الحقد الجنسي)، وشق الطريق إلى الإخـاء الإنساني وإلى المساواة. ولكن المدينة الغربية لا تزال عاجزة عن أن تنظر إلى ما وراء ذلك الأفق الضيّق من العداء الجنسي. إنَّ الإسلام لمج يعرف الطبقات الاجتماعية ولا حروب تلك الطبقات

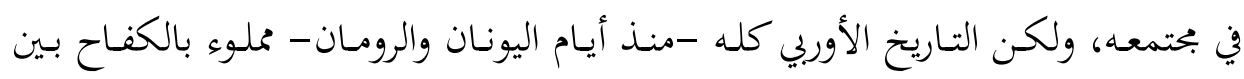

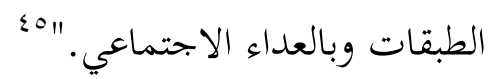

و (فايس) يرى، وهو يعاين الطغيان المادي للحضـارة الغربي، أنَّ تفوق ثقافة مـا أو

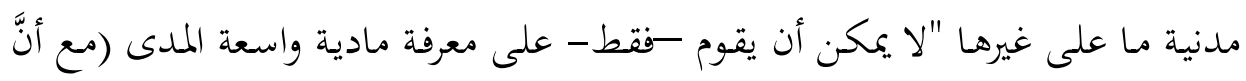
ذلك أمر مستحب)، ولكنه يقوم -كذلك- على نشاطها الخُلُقي، وعلى استطاعتها العظمى في أن تُعلّل، وفي أن تُوفِّق بـين نواحي الحيـاة الإنسـانية كلها، وفي هـذه الناحية

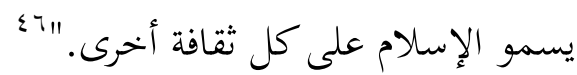

إذهما إذن -الشمولية والتوازن- اللذان وقفنـا عندها في معطيات (فايس)، وها هو

الآن يضعهما، جنباً إلى جنب مع الأخهاق الإسهلامية؛ لكي يهدّد الفروق الحاسمة بين

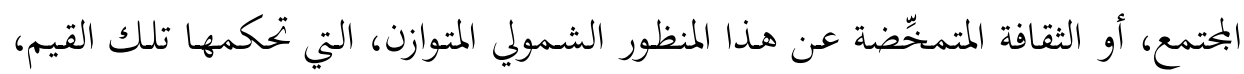

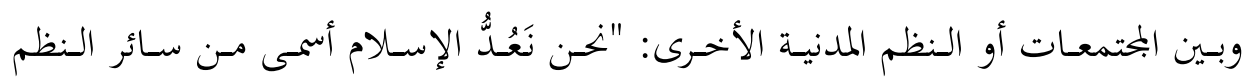

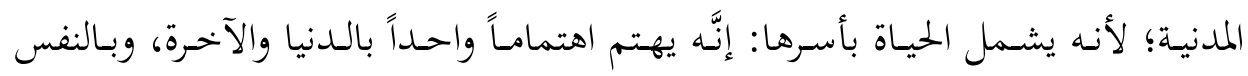

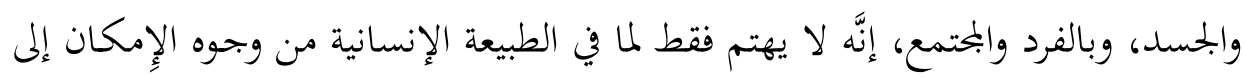

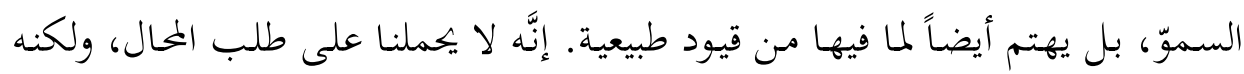

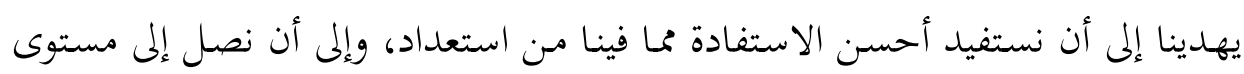

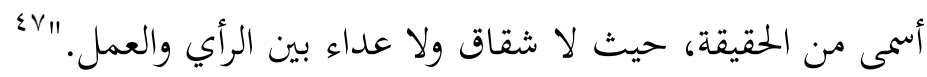

$$
\begin{aligned}
& \text { "؛ فايس، الإسلام على مفترق الطرق، مرجع سابق، صVVV. }
\end{aligned}
$$

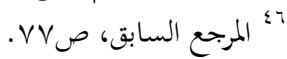

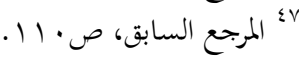


ورغم الفارق الكبير، في بتربة البحتمعات الإسلامية المعاصرة، بين ما هي عليه فعلاً، وماكانت عليه زمن التزامها المتألق بمعطيات هذا الدين، فِإن (فايس) وجد عبد وبر معايشته لمذه المحتمعات: "أن المسلمين كانوا يعيشون بطريقة تختلف عن الطريقة التي كان الغربيون

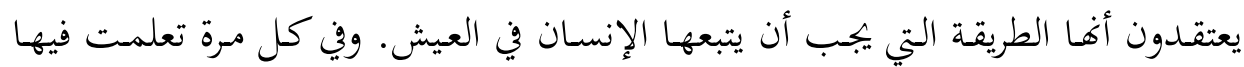

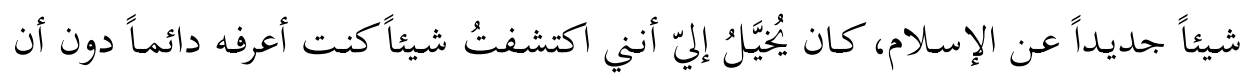

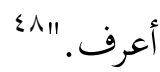

ذلك تـوق الإنسـان الذذي تعذبـه وتصــمه تناقضـات الحضــارة المعاصـرة وشـروخها بسائر بحاربها الاجتماعية المترعة بالتعاسة والشقاء، فهو إذ يلتقي بالمحتمعات الإسلامية،

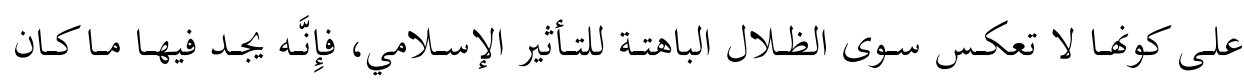
يبحثث عنه ويتوق إليه. و وفي ضوء هذا كله، يقـرر (فايس) أن الانتماء الإسلامي ليس

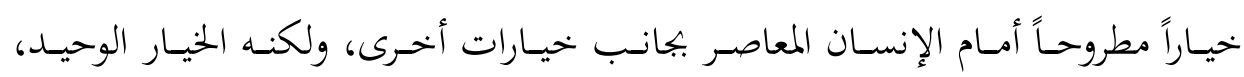

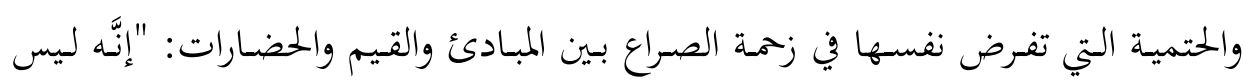

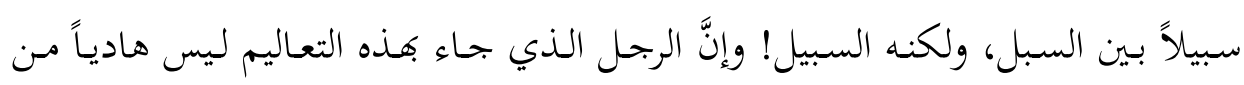

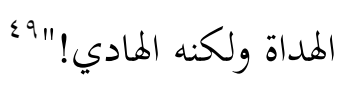

\section{سادساً: دين يتضمن سنة في تحققه العملي}

من بين العديد من الباحثين الغربيين الذين كتبوا عن سيرة الرسول (صلى الله عليه

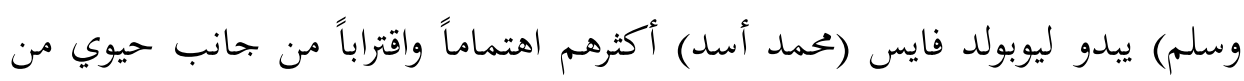
أكثر جوانبها أهمية، ذلك هو "السنة": فما الذي تعنيه؟ وما مكاها في خحارطة التشريع الإسالامي؟ وما مدى التوثيق الذي حظيت به؟ وما هي طبيعة التعامل التي يجب أن تنظم العلاقة بينها وبين المسلم؟ وما هي ردود الأفعال التي تمخضت عن هذا التعامل عبر التاريخ؟

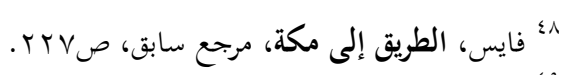

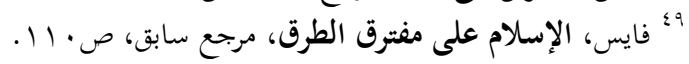


يعرّف فايس السنة بأفها: "المثال الذي أقامه لنا الرسول (صلى الله عليه وسلم) من

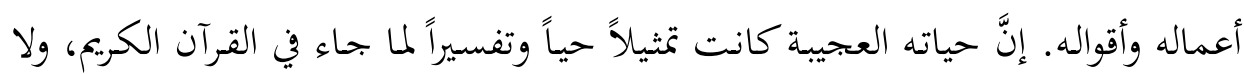

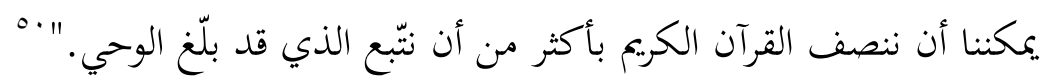
فهذا التعريف -على إيجازه- يكاد يلّم بسـائر عناصر المصطلح المقصود: فهنـاك

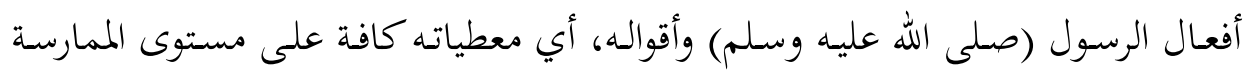

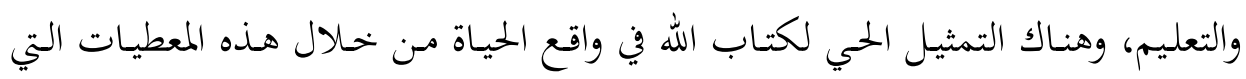
تؤدي مهمدة لا تقل أهمية، وهو التفسير الذي يوضّح ويفصّل مـا ورد في القـرآن الكريم

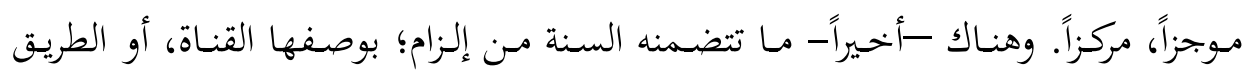
الوحيد المفضي إلى تنفيذ أمر الله كما بلّغه الوحي الأمين، وكما تثنَّل في كتاب الله. والسـنة بهـا المعـنى ليست حشـوداً مـن المفـردات السـلوكية، أو بحموعـة متفرقـة مـن التعاليم والإرشادات فحسب. إها وحدة مركبة، وبرنامج عمل يتميز بالشمولية والترابط،

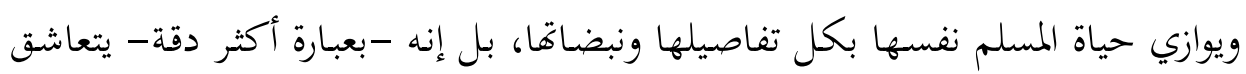

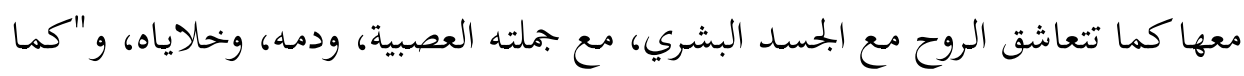

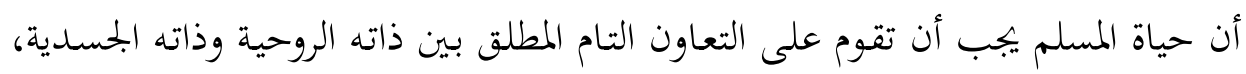

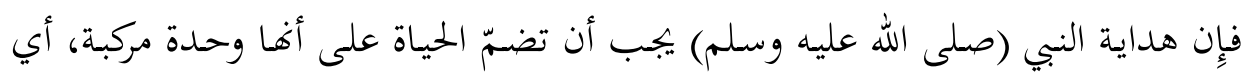

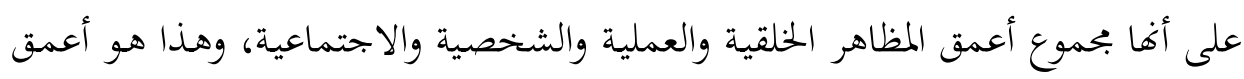

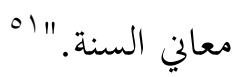

وإذا كانـت السـنة، على هـذا الأسـاس، هي التعبير المتكامـل عـن الإسـلام، يصـبح

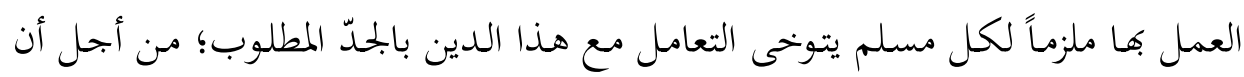

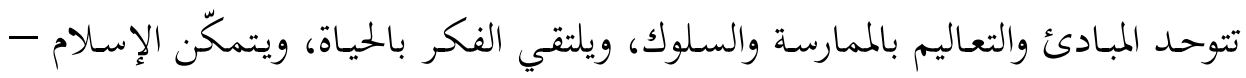

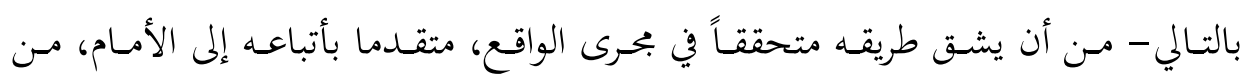

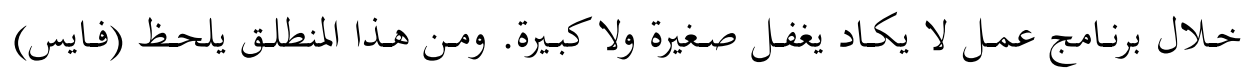

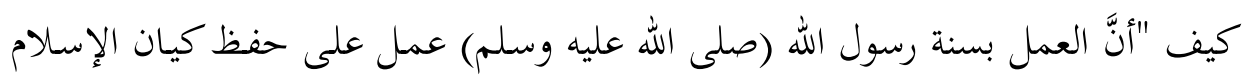

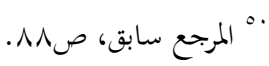

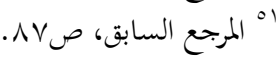




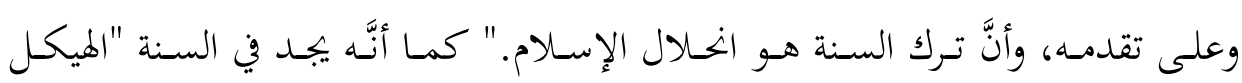

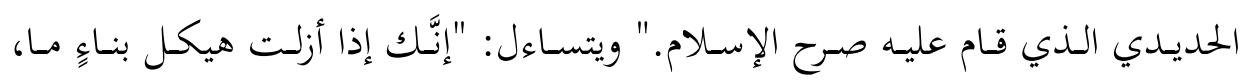

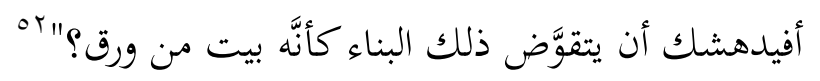

وعلى هـذا المستوى، أي على مستوى الإلـزام التشـريعي والسـلوكي والاجتمـاعي

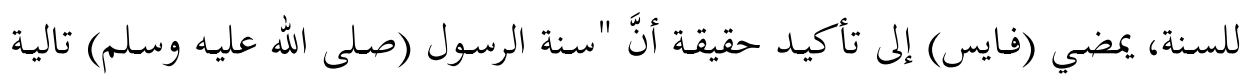

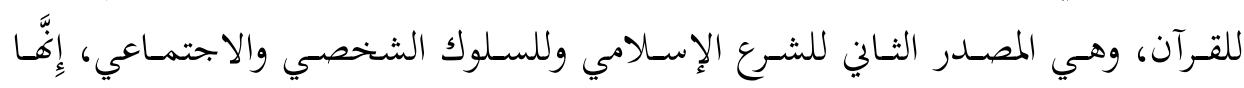

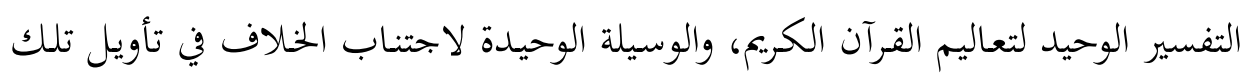

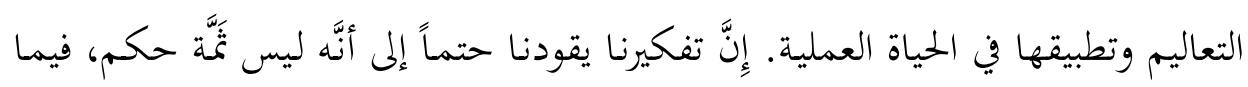

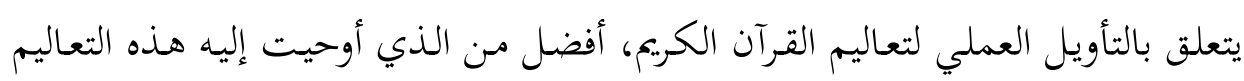

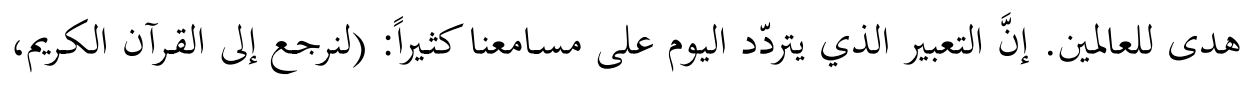

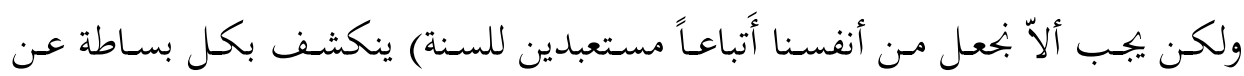

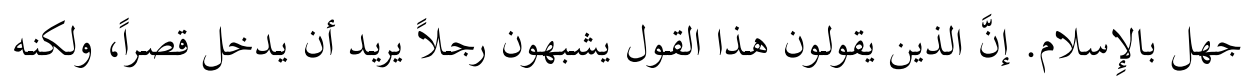

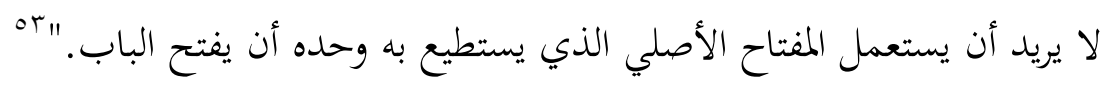

\section{سابعاً: السنة النبوية ومنهجها الفريد}

ولكن ما مدى مصداقية السنة على مستوى التوثيق التاريخي؟ وهل أنَّ مـا نُقِلَ عن

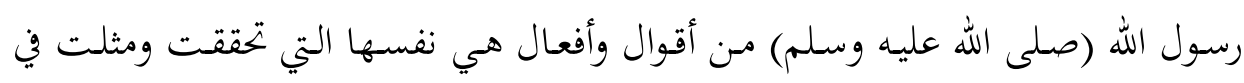

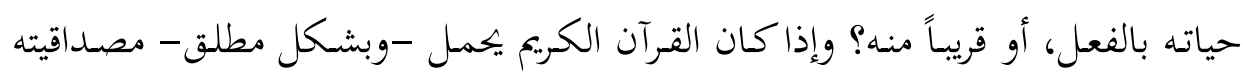

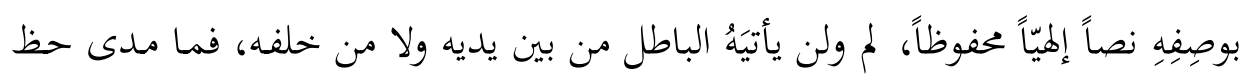

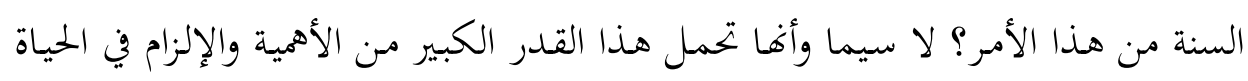
الإسلامية؟

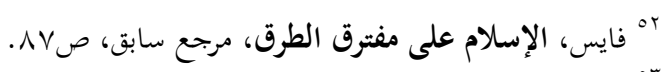

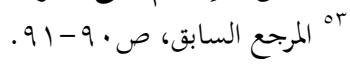


إن (فايس) لا يجعل هذه التساؤلات تفلت من بين يديه، وتبقى معلقة في الفضاء،

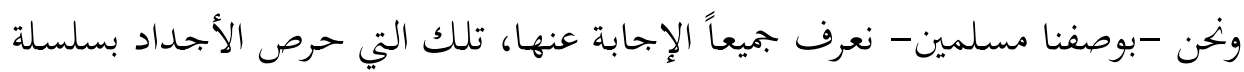

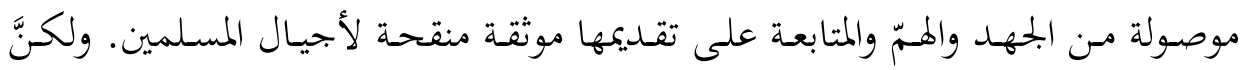
المطلوب هو مخاطبة العقل الغربي، والعقل العلماني الذي لا يسلّم بسهـولة بـأمر كهذا.

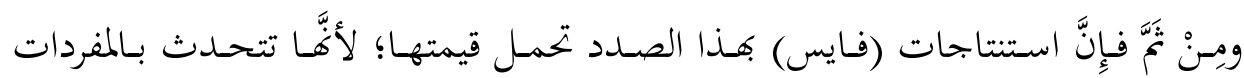
نفسها التي يدركها هذا العقل، وقد يقتنع بها أيضاً. فهـو يشـير مـثلاً إلى "الأثنر العظيم الـذي تركتهـ شخصـية الرسـول (صـلى الله عليـه

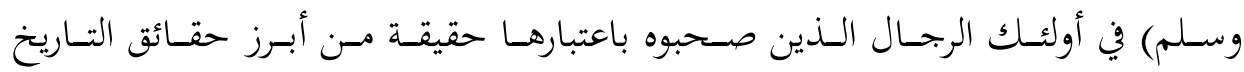

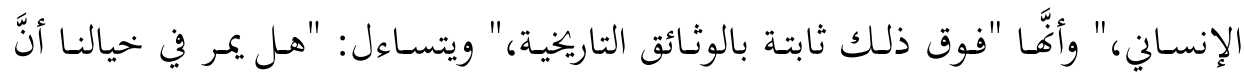
أولئك الرجال الذين كانوا على استعداد لأن يضحوا أنفسهم وما يملكون في سبيل رسول

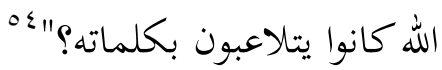

ويمضي (فـايس) إلى القـول بـأنَّ "الذذين عاشـوا في صحبة الرسـول (صلى الله عليـه وسلم) رأوا جميعُهُم في أقواله وأعماله أعظمَ الأهمية، لا لأنَّ شخصية الرسول (صلى الله عليه وسلم) أثرت فيهم فخلبت ألبابهم فقط، بل لأفَّم كانوا -أيضاً- على اعتقاد جازم بأنَّ ذلك كان أمراً من الله تعالى لتنظيم حياقم حتى في أدق تفاصيلها. كل ذلك اهتداء بالرسـول (صـلى الله عليـه وسـلم) واقتـاء بـه. مسن أجـل ذلك لم يسـتطيعوا أن يتنـاولوا الأحاديث بلا اكتراث، بل جربوا أن يتعلموها وأن يحفظوها عن ظهر قلب. "هنه

وهـو، على ضـوء الجههـود التوثيقيـة المذهلـة الـتي بـذهلا رجـال الحــديث في العصـور التالية للصحابة والتابعين، التي وضعت أصول مـنهج صارم في التوثيق والبحث العلمي يطرحُ تحدِيَهُه إزاءَ العقل الغربي، وأن يـدعم انتقاداته العاطفيـة لمصداقية الأحاديـث النبويـة

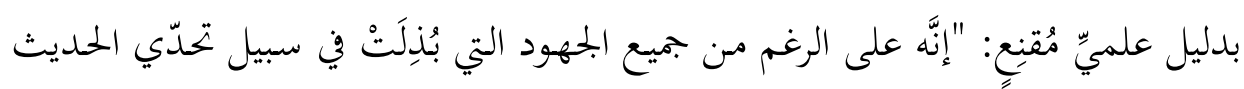


على أنَّه نظامُ مـا، فِإنَّ أولئكـك النقـاد العصريين مـن الشرقيين والغربيين لم يستطيعوا أن يدعموا انتقادهم العاطفي الخالص بنتائج من البحث العلمي. وإِنَّ من الصعب أن يفعل أحد ذلك؛ لأنَّ الجحامعين لكتب الحديث الأولى، لا سيَّما الإمامين البخاري ومسلماً، قد قاموا بكل ما في طاقة البشر عند عرض صحة كل حديث على قواعد التحديث عرضاً أشد كثيراً من ذلك الذي يلجأ إليه المؤرخون الأوربيون عادة عند النظر في مصادر التاريخ القديم. "الجه

ثم يخلص إلى القول بأن "رفض الأحاديث الصحيحة جملة واحدة أو أقساماً، ليس

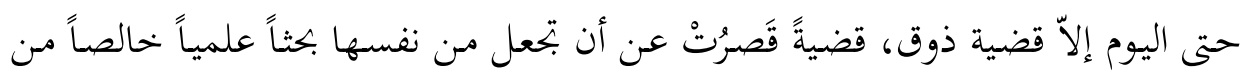

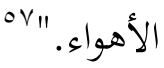

فهي -إذن- الميول والأهواء تسعى لأن تقول كلمتها في واحدة من أشد مرتكزات الإسلام أهمية، حتى إذا ما أتيح لها أن تفرض كلمتها، قدرت على هلى هدم الإسلام نفسه،

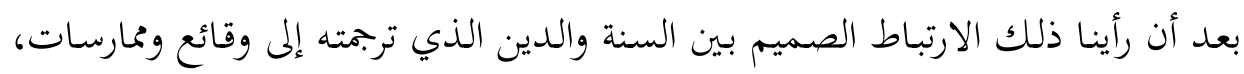
ولكنها لن تقدر؛ إذ إنَّ هنـاك، في الجهة الأخرى للظن والهوى: المنهج، والعلم، والنقد

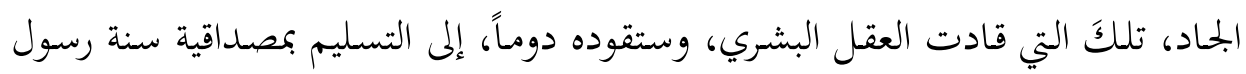
الله (صلى الله عليه وسلم).

ثامناً: السنة اقتداء بالرسول

سنكتفي بهذا القدر من الحديث عن مسألة التوثيق، هذه التي أشبعت بحثاً، ولنتابع (فايس) وهو يتحدث عن طبيعة التعامل مع السنة.. عن صيغ هذا التعامل التي تتأرجح

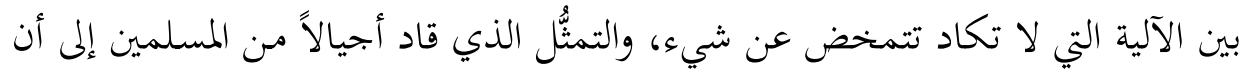

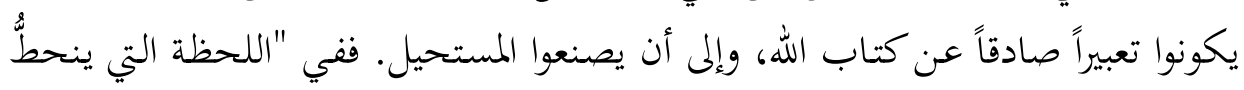

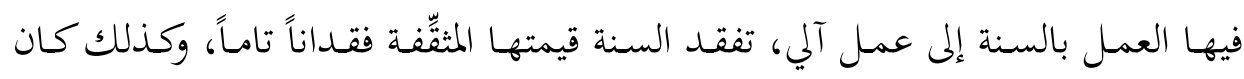

$$
\text { ro }
$$


شأن المسلمين في الأعصر الأخيرة. أمَّا الصحابة والتابعون الذين قاموا بكل مسعى لجعل كل دقيقة في حياقمم موافقة لماكان عليه الرسول (صلى الله عليه وسـلم)، فِإَِّم فعلوا

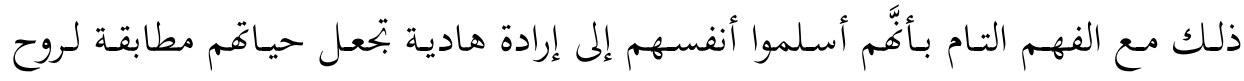

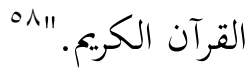

كيف يتم ذلك التطابق الباهر بين الحياة وتعاليم الله سبحانه؟ يبيبب (فايس) بأنَّ "العمل بالسـنة يجعل كل شيء في حياتنـا اليوميـة مبنياً على الاقتـداء بمـا فعلـه الرسـول

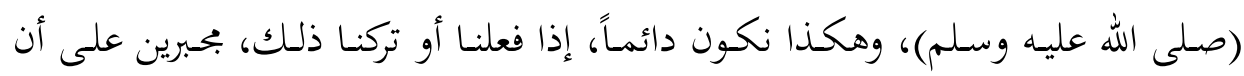

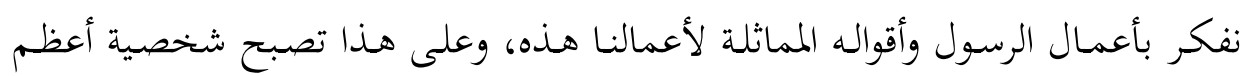

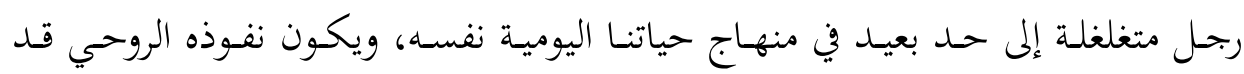

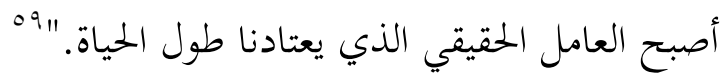

\section{تاسعاً: حب المسلمين لرسولهم في حياته وبعد مماته}

والحديث عن سنة رسول الله (صلى الله عليه وسلم) يقودنا إلى الحديث عن شخص

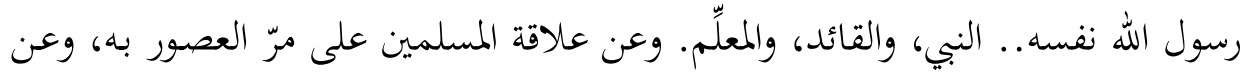

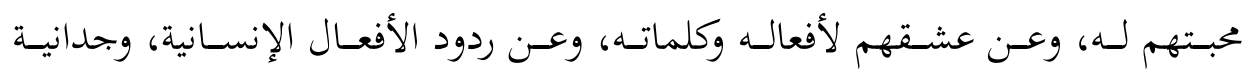

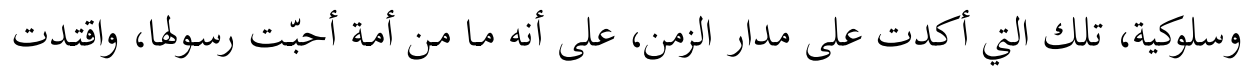

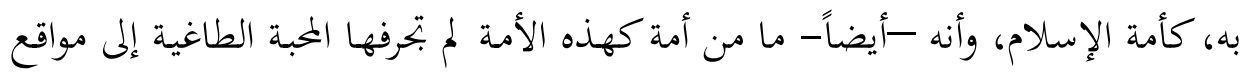
الشـرك والتأليه والصـنمية، ومـا كانـت الاستثناءات بقـادرة على أن تغطي على القعاعـدة أبداً. وليس هناك من رجل، "مضى على وفاته أكثر من ألف وثلاثمائة سنة، قد أصاب

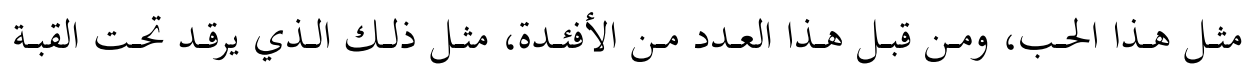

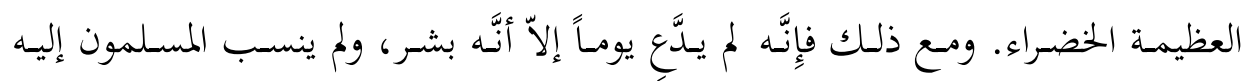
الإلوهية قط، كمـا فعل الكثيرون مـن أتباع الأنبياء الآخرين (عليهم السـلام) بعـد وفـاة

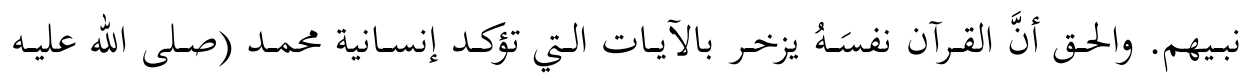




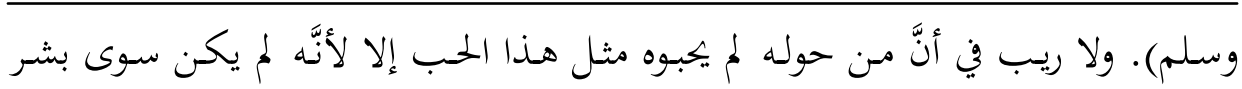

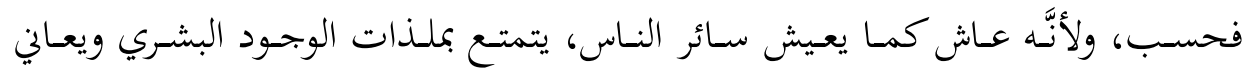

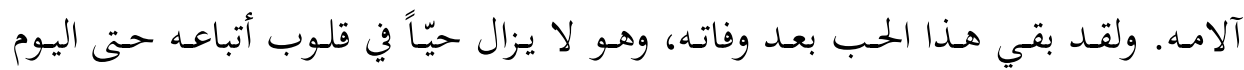

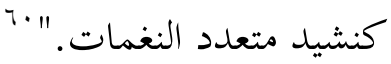

هذه وتلك تحمل أهميتها القصوى ها هنا، ونحن نتحدث عن سنة رسول الله (صلى

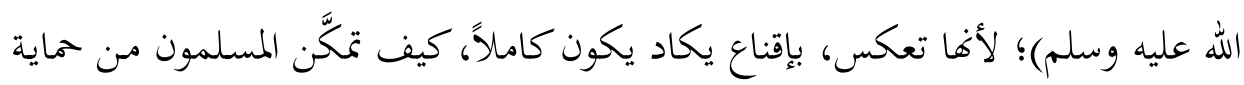

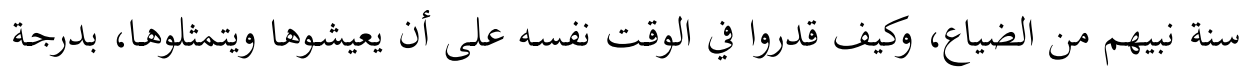
أو أخرى، فيتيحوا بذلك للإسلام نفسه أن يتحقق وأن يواصل الطريق.

والآن، وبعـد مـرور أربعة عشر قرناً على لحاق رسول الله (صلى الله عليه وسـلم)

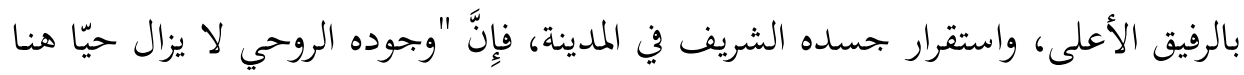

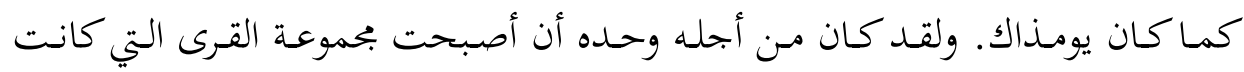

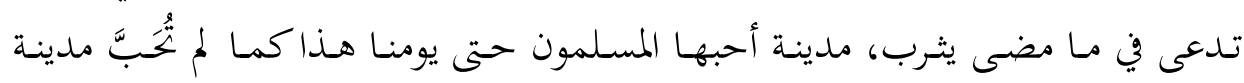

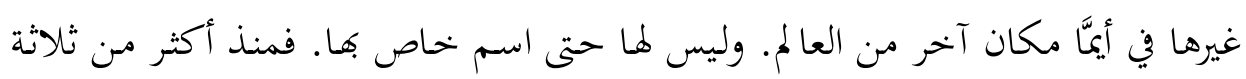

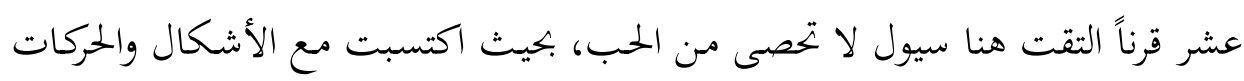

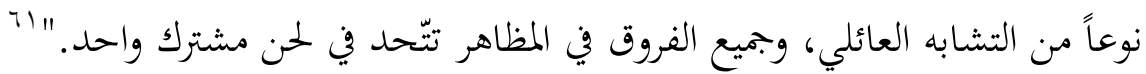

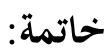

على كثرة ما كتبه الغربيون عن الإسلام، فإن معظم أعمالهم لم ترق إلى مـا قدمهـ

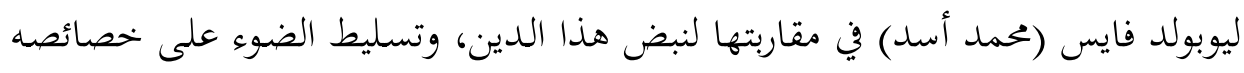

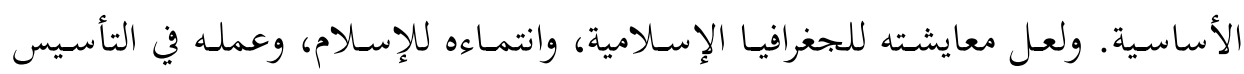

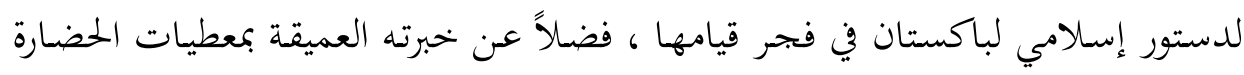

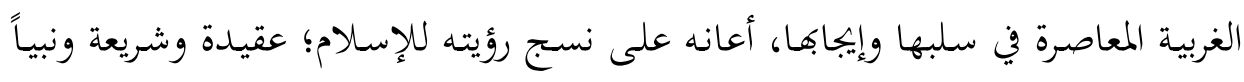


وحضـارة في العديـد مـن المؤلفـات، أبرزهـا ولا ريـب (الطريق إلى مكة))، و(الإسـلام على

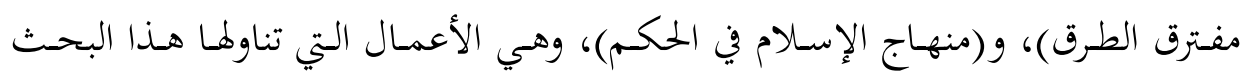
بالقراءة والمراجعة والتحليل.

وعلى الرغم مـن مـرور عقـود عديـدة على صـدور مؤلفاتـه تلـك، فـإن (الطريق إلى

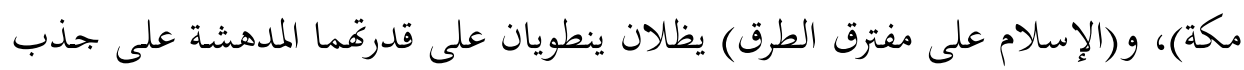

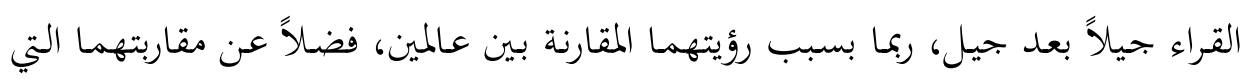

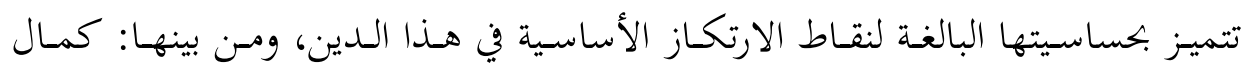
الإسلام وشموله لجوانب الحياة، وتوازنه، ومرونته التشريعية، وآفاقه التعبدية، ومبادؤه، وقيمه لئه

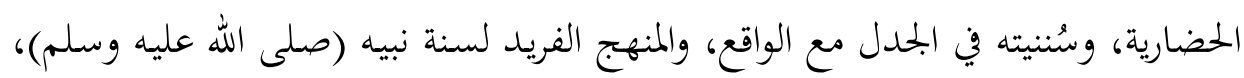

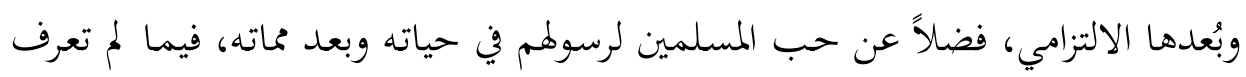
عشر معشاره عقيدة من العقائد أو دين من الأديان.

وتبقى أعمال (محمد أسد) منجماً خصباً لكل من يسعى إلى الكشف عن معطياقا

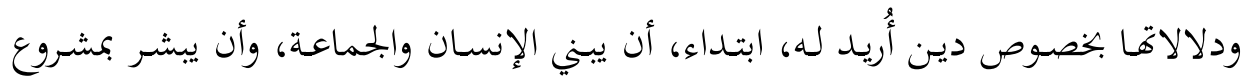
حضـاري متميز، يتجـاوز بقرآنه وسـنة نبيـه، عناصـر السـلب والـنقص في جـلّ المشـاريع الحضارية التي شهدها التاريخ البشري ولا يزال. 